\title{
Vínculos de formación y transmisión del conocimiento en la botánica del siglo XVIII: un análisis de redes sociales ${ }^{1}$
}

\author{
René Sigrist- Paris Observatory, SYRTE, France \\ Eric D. Widmer- University of Geneva, Switzerland*
}

\section{Resumen}

En esta contribución se desarrolla un enfoque de redes sociales sobre la formación de los botánicos europeos en el siglo XVIII.

En un período en el que el estudio de las plantas se estaba convirtiendo en un campo autónomo de investigación, la práctica de la botánica y otras ciencias relacionadas movilizó a un grupo muy diverso de actores. Para muchos de ellos, la iniciación en la ciencia de las plantas fue parte de sus estudios de medicina. Otros fueron formados como colaboradores de un erudito destacado en el contexto de un jardín real, a veces también en las facultades de filosofía. Otros fueron autodidactas. Con los datos biográficos disponibles hemos realizado un censo sistemático de los maestros y discípulos de un conjunto de 928 botánicos occidentales activos entre 1700 y 1830 . De este modo hemos identificado tres subgrupos, cada uno de ellos con distintas características y lógicas de desarrollo. Las características específicas de estos subgrupos se analizan desde una perspectiva histórica, con especial atención a los diversos contextos institucionales que los produjeron. El análisis de los datos muestra la creciente autonomía de la botánica respecto a la formación médica, así como el carácter cada vez más nacional de las escuelas dominantes, al menos en Francia.

Palabras clave: Historia de la botánica - Siglo XVIII - Contactos de formación Escuelas nacionales.

\begin{abstract}
This contribution develops a social network approach to the training of European botanists in the 18th century. In a period when the study of plants increasingly became an autonomous field of research, the practice of botany and related sciences mobilized a very diverse group of actors. For many of them, initiation to the science of plants was part of their medical studies. Others were trained as collaborators of an outstanding scholar in the context of a royal garden or elsewhere, sometimes also in philosophical faculties. Still others were self-taught. To the extent that biographical data were available, we made a systematic census of the masters and disciples of a set of 928 Western botanists active between 1700 and 1830. Three subsets were thus identified, each of them showing distinct characteristics and logics of development. The specific features of these subsets are discussed in a historical perspective, with a particular attention to the various institutional contexts which produced them. The data analysis basically shows the growing autonomy of botany with regard to medical training, as well as the increasingly national character of the dominant schools, at least in France.
\end{abstract}

Key words: History of botany $-18^{\text {th }}$ century - training links - National Schools.

\footnotetext{
${ }^{1}$ Artículo traducido del inglés por Irene Cruz Gómez.

* Los autores agradecen las revisiones anónimas de la revista REDES por sus muy útiles comentarios, así como a Natalia Tikhonov Sigrist por sus intentos de hacer que el estilo suene más inglés. Julia Carnine ha corregido también la versión inglesa del artículo.
} 
REDES- Revista hispana para el análisis de redes sociales

Vol.21,\#7, Diciembre 2011

http://revista-redes.rediris.es

\section{Introducción}

Hoy está plenamente reconocido el uso del análisis de redes sociales para desarrollar una mejor comprensión de las prácticas de investigación en la historia natural (Spary, 2008). En el campo específico de la botánica, como en otros, la introducción de una perspectiva de redes implica la aceptación de una concepción de la ciencia como una cuestión de interacción entre académicos, así como una sucesión de paradigmas teóricos. La consecuencia obvia consiste en cambiar el enfoque de la historiografía, desde las investigaciones tradicionales basadas en ideas, teorías y descubrimientos, hacia un análisis basado en la organización social de la investigación. En el caso de la botánica, esto significa que el intercambio epistolar, las transferencias de especímenes y otras interacciones sociales han pasado a un primer plano (Dauser $\&$ al., 2008). Más allá del estudio de la redes ego-centradas, se han hecho intentos de desarrollar una representación visual de la institución académica (Stuber, Haechler, Krempel y Ruisinger, 2008), de realizar un conjunto estándar de ilustraciones botánicas (Nickelsen, 2008) o de describir un sistema local de transferencia de las plantas (Stuber, 2008). Sin embargo, todavía no se ha esbozado ningún estudio global del campo de la botánica Europea. El presente artículo pretende introducir una perspectiva para el período 1670 a 1830 , cuando la organización de la ciencia estaba dominada por unas pocas Academias Reales. A través de la descripción analítica de los vínculos de formación entre maestros y discípulos, el objetivo que se persigue es la caracterización de los canales principales que condujeron al emergente campo de la botánica.

Antes de que la figura del científico profesional se convirtiera en la norma dominante en la segunda mitad del siglo XIX, los miembros de la "República de la Ciencia" procedían de diferentes orígenes sociales y culturales. La formación de un campo científico, ya sea especializado o no, requería que los actores involucrados compartieran algunos ideales y normas comunes, y que fueran capaces de cooperar de una manera eficiente. Como para cualquier otro tipo de investigaciones colectivas, el estudio de las plantas generó distintos tipos de vínculos entre los participantes. Entre los botánicos, la interacción más común tomó la forma de intercambios de cartas y muestras. Se pueden considerar las influencias intelectuales como otro tipo de vínculo, a pesar de que las pistas que así se dejan sean menos evidentes que en el caso de las ediciones y traducciones de las obras de los compañeros. También se establecían conexiones más directas mediante visitas personales, viajes y publicaciones conjuntas. Consideradas desde el punto de vista de las redes, estas formas de colaboración más estrecha constituían una 
REDES- Revista hispana para el análisis de redes sociales

Vol.21,\#7, Diciembre 2011

http://revista-redes.rediris.es

especie de columna vertebral de la "República de los Botánicos", mientras que el intercambio de información y materiales representaba su funcionamiento ordinario. Las fronteras de este campo social e intelectual eran, obviamente, inciertas y móviles. Sin embargo, el acceso al pequeño núcleo de profesionales de pleno derecho que vivían de la botánica, se regulaba a través de una combinación de formación, mecenazgo y, en ocasiones, también de vínculos familiares. El presente artículo se centra en los vínculos de formación entre maestros y discípulos, que se entablaron entre los botánicos para la socialización en los principios de su ciencia.

Partiendo de la idea de que el objetivo final de la ciencia es el establecimiento de las verdades universales sobre la naturaleza, notamos que a menudo se obvia la influencia de la ubicación de la práctica científica, así como el estatus de sus diversos actores. Desde que emergió el ideal de la "República de las Letras" en la Europa del Renacimiento, el desarrollo de la academia se ha concebido como un espacio universal que requiere de la colaboración entre los estudiosos de todos los orígenes, las condiciones sociales y las denominaciones (Bots y Waquet, 1997). Antes del triunfo del positivismo, los filósofos y los académicos de la Ilustración proclamaron el carácter universal de la práctica científica como una condición previa de su objetividad. Incluso entre los historiadores, el punto de vista dominante durante mucho tiempo ha sido que el buen conocimiento científico no se vea afectado por las condiciones sociales, culturales ni locales. La ciencia de la Ilustración en particular, todavía se considera inmune al veneno del nacionalismo científico que contaminó los siglos XIX y XX. Sin embargo, hemos demostrado previamente que, en el siglo XVII, las grandes monarquías compitieron por el dominio sobre el "imperio de la ciencia", como se disputaron el imperio de los mares (Sigrist, 2008a). Los científicos se vieron confinados a ciertos límites geográficos en sus intercambios de correspondencia (Sigrist, 2008b; Sigrist 2009). Por tanto, es de esperar, incluso si va en contra de la corriente, que la botánica de la Ilustración tuviera también una geografía. 
REDES- Revista hispana para el análisis de redes sociales

Vol.21,\#7, Diciembre 2011

http://revista-redes.rediris.es

\section{La noción de contactos de formación y el origen nacional de los académicos}

La relación maestro-discípulo es de crucial importancia para la transmisión del conocimiento y sus desarrollos posteriores. A las generaciones más jóvenes se les transmite una iniciación en una forma de erudición especializada, y para la generación de más edad se asegura la difusión de sus principios y la continuidad de su fama. Por lo tanto, no es una relación totalmente unilateral, ya que transmite un cierto grado de interdependencia entre maestros y discípulos. A menudo se asocia con otros tipos de vínculos, como la influencia intelectual, los patrocinios, las colaboraciones y en algunos casos, los vínculos familiares. La influencia intelectual, que es la más propensa a confundirse con los vínculos de formación, no requiere de ninguna relación directa y personal, sino sólo de una deuda reconocida a la importancia teórica o metodológica de otro experto. Para un botánico, tal influencia intelectual, por ejemplo, se establece mediante el uso de un sistema de clasificación ideado por otro experto.

La relación maestro-discípulo o el vínculo de formación, es una relación personal entre dos individuos determinada localmente, en la que uno proporciona una enseñanza formal al otro, ya sea dentro del contexto universitario o no. Cuando el maestro es también el director de tesis del estudiante, o cuando el estudiante de doctorado también trabaja como ayudante de laboratorio de su director, el enlace tiene una dimensión doble o incluso triple. Hemos establecido este tipo de enlaces cuando se mencionan en una biografía impresa de cualquier discípulo o maestro, sobre todo entre los recogidos en el Sistema Mundial de Información Biográfica (WBIS por sus siglas en inglés). Evidentemente, esto depende en gran medida del estado actual de la historiografía, ya que un estudio exhaustivo de los documentos primarios (por ejemplo, de los registros universitarios) es inviable en una escala tan grande. 
REDES- Revista hispana para el análisis de redes sociales

Vol.21,\#7, Diciembre 2011

http://revista-redes.rediris.es

Dada la diversidad de los actores en la "República de los botánicos", y la gran variedad de sus localizaciones, orígenes y condiciones sociales, los vínculos que éstos desarrollaron durante sus años de formación, o más adelante en su carrera, jugaron un papel crucial en la creación de un campo científico dedicado a la botánica. A nivel local, este campo se constituyó principalmente de lazos familiares y patrocinios. A nivel mundial, se basó en intercambios intelectuales o materiales y en influencias. $Y$ en algún lugar intermedio, existieron diversas formas de cooperación (como las publicaciones o los viajes conjuntos, las investigaciones comunes). Está aún por determinar el alcance exacto de los vínculos de formación, así como el papel que desempeñaron en el desarrollo de una comunidad internacional de botánicos.

Para averiguar si las relaciones entre maestro y discípulo tenían una base principalmente internacional, nacional o local, es preciso conocer la movilidad geográfica de los estudiantes de botánica, y por lo tanto, identificar antes su origen nacional. Dado que el significado cultural de las fronteras, y en algunos casos, incluso su significado político, estaban lejos de ser claros en el siglo XVIII, será necesario hacer algunas precisiones sobre el modo en que estas entidades territoriales se han definido para la presente investigación. De hecho, algunos países importantes como Alemania o Italia, estaban divididos en varios estados. El Sacro Imperio Romano Germánico incluía potencias reales (Prusia, Baviera, Sajonia, Austria), así como pequeñas soberanías locales de estatus incierto. El Sacro Imperio también incluía algunos núcleos de naciones más pequeñas (los checos), hasta que se unieron a los húngaros y otras nacionalidades en el Imperio Austríaco (formalmente proclamado en 1806). Lo mismo les sucedió a las gentes del Báltico dentro del Imperio Ruso, a los finlandeses en el Imperio Sueco, a los irlandeses en el Reino Unido, a los noruegos en Dinamarca, e incluso a los polacos, después de las particiones sucesivas de su país. Sin embargo, no hay un criterio simple que se pueda utilizar para determinar, en cada caso, quién pertenecía a estos grupos étnicos. La configuración cambiante de las fronteras añade una dificultad adicional, especialmente entre 1792 y 1815 . Por lo tanto, una investigación sobre la movilidad geográfica no puede basarse en las naciones tal como las concebimos hoy, ni en los Estados tal como existían en el siglo XVIII. Dado que la cuestión que aquí se trata es la localización espacial y la movilidad espacial de los estudiantes, y no su identificación nacional o imperial, puede que resulte suficiente considerar las entidades geográficas que tienen un significado 
REDES- Revista hispana para el análisis de redes sociales

Vol.21,\#7, Diciembre 2011

http://revista-redes.rediris.es

cultural o territorial, sea cual sea su naturaleza política (nación, imperio, estado federal o colonia). El término "nacional" se utilizará en este documento como un atajo para referirse a estas entidades, que tenían un significado territorial o cultural en la Europa del siglo XVIII. La nacionalidad de los botánicos se determina de acuerdo con sus orígenes. Considerar múltiples nacionalidades teniendo en cuenta los lugares de actividad no aporta grandes diferencias, a excepción de Rusia, que importó muchos académicos, y tal vez de Suiza, que exportó muchos otros.

Cerca del $74 \%$ de los botánicos que vamos a considerar provienen de cuatro entidades territoriales de carácter nacional: Francia, Gran Bretaña (Irlanda incluida), "Alemania" (es decir, todos los territorios de habla alemana del Sacro Imperio Romano Germánico con la excepción de los dominios de los Habsburgo) y de "Italia" (que incluye a todos los Estados de habla italiana). El 25\% restante de los botánicos pertenecen principalmente a otras nueve entidades: Suecia (incluyendo Finlandia), los Países Bajos, Suiza, el Imperio Ruso, el Imperio de Austria, los Estados Unidos (colonia británica hasta 1776), Dinamarca (incluyendo Noruega), España y Portugal. Sólo un 1 o un $2 \%$ procedía de otros territorios europeos (Polonia, Bélgica) o de las colonias (México, Colombia, Sudáfrica).

Investigaciones anteriores (Sigrist, 2008b y 2009) han mostrado que una gran mayoría de los intercambios epistolares relevantes del siglo XVIII se realizaron entre académicos que hablaban la misma lengua vernácula o que pertenecían a una misma entidad territorial o cultural, especialmente para las más grandes (Francia, Gran Bretaña, "Alemania", "Italia"). Posiblemente, este hecho no ha sido visible hasta el momento a causa del carácter y extensión internacional de las redes personales de un puñado de botánicos destacados como Carl von Linné, Albrecht von Haller o Joseph Banks. A pesar de estas limitaciones nacionales, las cadenas de intercambios epistolares permitieron que las noticias viajaran de un modo más eficiente desde los principales centros de la "República de las letras" hasta sus partes más remotas, mientras que las traducciones y las influencias intelectuales se saltaban las fronteras nacionales o lingüísticas con mayor facilidad. A excepción de Francia, el uso del latín seguía siendo la norma en la formación en botánica, de modo que no esperamos que las fronteras lingüísticas limitaran la movilidad de los estudiantes. 
REDES- Revista hispana para el análisis de redes sociales

Vol.21,\#7, Diciembre 2011

http://revista-redes.rediris.es

\section{Definir una muestra de botánicos del siglo XVIII}

Definir a los botánicos como hombres de ciencia que han recibido una formación reglada en la botánica, probablemente sería una simplificación excesiva para la realidad del siglo XVIII. A pesar de que sus contemporáneos tenían pocas oportunidades de percibir a los botánicos como un grupo independiente de expertos, difícilmente alguno reduciría un inventario de los eruditos en botánica a aquellos con una alta formación. Carl von Linné, quien trató de establecer una taxonomía detallada de los botánicos en su Philosophia botanica (1751), no separó a los especialistas académicos de los no académicos. Su objetivo era de hecho más prescriptivo que descriptivo, ya que él sólo quería definir una nueva disciplina y a sus practicantes de una manera que expresara sus propios ideales taxonómicos (Müller-Wille, 1999). A Linné le importaba poco la realidad histórica; la noción de Respublica Botanici (República de los botánicos) que utilizó en su correspondencia con Albrecht von Haller $(1737)^{2}$ tuvo poco éxito. La identidad de los botánicos como un grupo independiente de académicos, de hecho, permaneció incierta hasta principios del siglo XVIII, e incluso tal vez hasta 1750. La práctica de una ciencia no implica necesariamente tener un reconocimiento como especialista de la misma, ni mucho menos un profesional, y esta afirmación es tan cierta para los botánicos como, por ejemplo, para los químicos (Hannaway, 1975). Por lo tanto, es preciso distinguir la aparición de la botánica como ciencia de su identificación como una práctica social.

Linné mismo consideraba que la botánica se inició en el siglo XVI con la posibilidad de establecer una diagnosis, es decir, de identificar la verdadera naturaleza de una planta. Por supuesto, las plantas se habían estudiado ya mucho antes, y Linné mismo menciona un buen número de "padres de la botánica", desde los famosos Teofrasto, Plinio y Dioscórides en la antigüedad hasta otros pertenecientes a la Edad Media latina y árabe. Sin embargo, su incapacidad para establecer la diagnosis no les da derecho a ser considerados como verdaderos botánicos. Según Linné, la botánica moderna comenzó con el uso del sistema sexual de las plantas, que se hizo posible gracias a los descubrimientos de la naturaleza sexual de las plantas de Camerarius (1694) y, sobre todo de Sébastien Vaillant (1717). El uso

\footnotetext{
2 The Linnaean Correspondence, edición electrónica preparada por Eva Nyström y la Sociedad Sueca Linneana, Uppsala, y publicado por el Centro internacional de estudios del siglo XVIII, Ferney-Voltaire. La carta a Haller tiene fecha del 8 de Junio de 1737.
} 
REDES- Revista hispana para el análisis de redes sociales

Vol.21,\#7, Diciembre 2011

http://revista-redes.rediris.es

propio que hizo Linné de la sexualidad de las plantas para establecer un nuevo sistema de clasificación lo inició en 1737. Ahora bien, si la botánica se estableció desde el Renacimiento como una categoría utilizada para clasificar a un género de libros en las bibliotecas o para definir un tema de la enseñanza universitaria, ¿qué sucedió con los botánicos? La creación, en la década de 1540, de los primeros jardines universitarios no implicó una clara distinción entre el botánico, que estaba encargado de supervisar el jardín, y el profesor de medicina, que enseña la materia médica (farmacología), como parte de sus tareas académicas. De hecho, a menudo ambas funciones recaían en una sola persona. Los primeros botánicos a sueldo surgieron a mediados y finales del siglo XVII, ya sea como miembros de una academia real o como viajantes naturalistas patrocinados por el rey. La palabra "botánico" data probablemente de esta época, pero en comparación con el término "botánica", tuvo un escaso uso hasta mediados del siglo XVIII (Tabla 1). Por lo tanto, es lógico concluir que a pesar de la existencia de un puñado de botánicos profesionales desde finales del siglo XVII, su reconocimiento social como un grupo especializado de académicos no ocurrió antes de la década de 1750 o hasta la década de 1780. Cabe destacar que es también hacia mediados del siglo XVIII que los botánicos comenzaron a discutir sobre las fronteras de su disciplina (Bungener, 2007).

\begin{tabular}{|c|c|c|c|}
\hline Año & English & French & German \\
\hline $1700-1750$ & $3 \%$ & $2 \%$ & $2 \%$ \\
\hline $1751-1780$ & $5 \%$ & 12 & 13 \\
\hline $1781-1800$ & $11 \%$ & 31 & 59 \\
\hline $1801-1810$ & $27 \%$ & 41 & 48 \\
\hline $1811-1820$ & $29 \%$ & 45 & 49 \\
\hline $1821-1830$ & $27 \%$ & 44 & 36 \\
\hline
\end{tabular}

Tabla 1: Relación entre el uso de la palabra "botánico" en comparación con la palabra "botánica" en el siglo XVIII (investigación llevada a cabo en enero de 2010 sobre la base de los textos en inglés, francés y alemán, disponibles en http://books.google.com). A pesar de las limitaciones lingüísticas y las diferencias significativas entre los idiomas, claramente se deduce que hasta 1780 , los especialistas en botánica fueron menos claramente percibidos en las sociedades europeas que la ciencia de las plantas en sí. En cuanto a la palabra "botany", apareció en el siglo XVII, mientras que la palabra francesa "botanique" ya existía en el siglo XVI. 
REDES- Revista hispana para el análisis de redes sociales

Vol.21,\#7, Diciembre 2011

http://revista-redes.rediris.es

Con la perspectiva del tiempo, los historiadores están probablemente en una mejor posición que los contemporáneos para identificar a los especialistas que practicaban la ciencia botánica. Pero, ¿qué criterios son los más importantes? Linné estableció una distinción entre docenas de diferentes tareas, cada uno de las cuales sería ejecutada por un tipo específico de actores (Sigrist, 2011A). Los botánicos principales, sin duda eran capaces de combinar muchas de estas tareas, cuando no todas ellas, mientras que otros, especialmente los considerados por Linné como meros "botanófilos", sólo realizarían una o dos. El hecho de publicar no siempre se ha considerado uno de los criterios principales $y$, en el intento reciente de proponer una clasificación de botánicos, (Steinke, 2008; Haechler, 2008) no se considera como un factor crucial.

La "República de los botánicos" sin duda ha incluido diversos tipos de actores cuya característica común es la colaboración en el estudio de las plantas, y en particular, el intercambio material y académico. Para una pequeña élite, el hecho de pertenecer a academias o tener posiciones formales dentro de los jardines botánicos, universidades u otras instituciones de enseñanza, facilitó que fueran socialmente identificados como botánicos. El simple criterio de afiliación académica en alguna de las seis academias más importantes del período entre 1700 y 1830 (en las ciudades de París, Londres, Berlín, San Petersburgo, Estocolmo, Bolonia) permite la identificación de un primer corpus de 301 botánicos especializados. Otro criterio contemplará las publicaciones importantes, que justifiquen su presencia en el Catálogo Histórico de Científicos de Robert M. Gascoigne (1984), lo que permite ampliar nuestro corpus de botánicos especializados a 743 personas. Este conjunto se puede ampliar en dos direcciones más:

$1^{\circ}$. Considerando diversas categorías de botánicos menores, empezando por aquellos incluidos en la obra de R.K.Brummitt y C.E. Powell Autores de nombres de plantas (1992), y en la de Frans A. Stafleu y Richard S.Cowan Literatura taxonómica (1976-1988), así como otros amateurs cuya actividad ha dejado alguna huella a nivel local.

$2^{\circ}$. Registrando a botánicos no especializados que practicaban la ciencia de las plantas además de la historia natural o la medicina, incluso de modo esporádico. Aparte de los verdaderos botánicos, especializados en taxonomía, anatomía de las plantas y medicina botánica, también es posible considerar a los fisiólogos vegetales, los agrónomos, los jardineros, los trabajadores en viveros y los ingenieros forestales, así como a otras categorías de botánicos no especializados. 
REDES- Revista hispana para el análisis de redes sociales

Vol.21,\#7, Diciembre 2011

http://revista-redes.rediris.es

Para establecer cierta sistematicidad entre estas categorías, se podría considerar a los botánicos en función de su fama y del grado de implicación en la disciplina. Evidentemente, los dos aspectos están más o menos relacionados, pero eso no debería ser óbice a efectos de utilizarlos para clasificar a los participantes en la empresa botánica, ni a inducir sub-categorías con fines estadísticos. En relación a la supuesta importancia de su contribución científica o su estatus dentro de la comunidad científica, podríamos distinguir entre: a) académicos notables, b) académicos de segundo rango, c) amateurs. En relación a su grado de participación en el estudio de las plantas, estos académicos caben dentro de las siguientes categorías: 1) botánicos especialistas, 2) botánicos no especialistas, 3) botánicos ocasionales. Al combinar ambos criterios, se hace teóricamente posible definir por lo menos 9 categorías formales de actores, lideradas por el botánico notable especializado (a1) y el botánico especialista de segundo rango (b1) (Tabla 2 ). Les siguen grupos menos prestigiosos de académicos no especializados de importancia mayor o menor (a2, b2), y por categorías de actores con todavía menor implicación (c1, c2, a3, b3), hasta el amateur ocasional en botánica (c3). Al definirlo de este modo, la "República de los Botánicos" del siglo XVIII puede haber incluido, en diversos grados, decenas de miles de actores a lo largo del mundo occidental. Entre ellos, sólo unos pocos centenares pertenecientes a las principales categorías jugaron un papel significativo en el establecimiento de la disciplina.

\begin{tabular}{|l|c|c|c|}
\hline & $\begin{array}{c}\text { a. Académicos } \\
\text { notables }\end{array}$ & $\begin{array}{c}\text { b. Académicos de } \\
\text { Segundo rango }\end{array}$ & $\begin{array}{c}\text { c. Académicos menores } \\
\text { y amateurs }\end{array}$ \\
\hline $\begin{array}{l}\text { 1. Botánicos } \\
\text { especializados }\end{array}$ & $\begin{array}{c}\mathbf{1 6 5} \text { identificados } \\
(100 \%)\end{array}$ & $\begin{array}{c}\mathbf{5 7 4} \text { identificados (100 } \\
\%)\end{array}$ & $\begin{array}{c}\text { c. } 1100 \\
\text { "botanófilos" }\end{array}$ \\
\hline $\begin{array}{l}\text { 2. Botánicos no } \\
\text { especializados }\end{array}$ & $\begin{array}{c}\mathbf{7 1} \text { identificados } \\
\text { (c. } 25 \%)\end{array}$ & $\begin{array}{c}\mathbf{1 1 8} \text { identificados } \\
\text { (c. 12-15 \%) }\end{array}$ & "herbalistas" \\
\hline $\begin{array}{l}\text { 3. Botánicos } \\
\text { ocasionales }\end{array}$ & $\begin{array}{c}\text { Algunos identificados } \\
\text { (Buffon, Laxman) }\end{array}$ & $\begin{array}{c}\text { Algunos identificados } \\
\text { (Rousseau, Karpinski) }\end{array}$ & "dilettanti" \\
\hline
\end{tabular}

Tabla 2: Categorización formal y estimación del número de personas relacionadas con la botánica entre 1700 y 1830.

El uso de criterios formales para la identificación permite determinar los miembros de cada categoría de actores. 
REDES- Revista hispana para el análisis de redes sociales

Vol.21,\#7, Diciembre 2011

http://revista-redes.rediris.es

A) Los académicos notables se han identificado por sus afiliaciones (ya sea como miembros, socios, o corresponsales) por lo menos en dos de entre seis grandes academias de la época, o por su inclusión en el Diccionario de Biografía Científica (DSB por sus siglas en inglés). Entre los 1640 académicos de esta categoría que fueron activos entre 1700 y 1825, hay 165 que pueden identificarse como botánicos especialistas (a1), siendo la botánica su principal área de investigación. Por lo menos otros 71 académicos son mencionados como botánicos no especialistas (a2) en el DSB y otros registros académicos: son actores que sin duda han practicado la botánica como un área de investigación subsidiaria, o son especialistas en materias vecinas como la agronomía o la fisiología vegetal. Sin embargo, según un estudio monográfico sobre los académicos activos en Rusia (Elina, 2008), se puede suponer que el total de personas dedicadas a algún tipo de investigación botánica bajo otras disciplinas como la medicina, la historia natural, la farmacia o incluso la química llegaría a cuadruplicar la cifra. Además, la categoría de académicos notables incluye un número indeterminado de individuos que sólo practicaban la botánica ocasionalmente (a3). Algunos de ellos pueden identificarse, como el cura finés y geólogo Eric Laxman o el famoso Buffon, quien dirigió el Jardin du Roi en París durante 49 años, isin herborizar una sola vez!

B) La categoría de académicos de segundo rango incluye a todas las otras personas afiliadas a alguna de las seis principales academias del siglo XVIII, o que están registradas en el Catálogo Histórico de Científicos y de Libros Científicos de Robert M. Gascoigne (1984). Entre los 4248 académicos de este tipo que estuvieron activos entre 1700 y 1825, 574 pueden considerarse como botánicos especialistas (b1), pero muchos más practicaban la botánica de un modo menos regular, ya sea como disciplina "secundaria" (b2), ya sea como actividad ocasional (b3). El grupo b2 incluye una mayoría de médicos, mientras que el grupo b3, compuesto de botánicos por afición, está formado por académicos especializados en diversas áreas de investigación, incluyendo a hombres de letras y filósofos, tal como Jean-Jacques Rousseau.

C) Finalmente, los de la tercera categoría de académicos menores y amateurs (c) pueden ser definidos como los que practicaban la botánica de una forma menos intensa o menos exitosa. A nivel local, pueden identificarse en base a: las publicaciones (por lo menos una); las posiciones institucionales (como catedráticos de botánica, directores de jardines botánicos, o cuidadores de herbolarios); la cooperación con botánicos de primer rango; miembros de sociedades botánicas; 
REDES- Revista hispana para el análisis de redes sociales

Vol.21,\#7, Diciembre 2011

http://revista-redes.rediris.es

posesión de un jardín botánico o un herbolario. Los más perseverantes (c1) pueden asociarse a los "botanófilos" de Linné. De acuerdo con investigaciones locales desarrolladas en Ginebra, San Petersburgo, Göttingen y Florencia, su cifra total puede estimarse en 1,5 veces la cantidad de especialistas en las categorías a1 y b1 juntas.

Otra categoría que hemos llamado "herboristas" (c2), puede definirse como un grupo dedicado a la recolección de plantas medicinales, que podría incluir muchos farmacéuticos, párrocos, y miembros de clases rurales y urbanas, con una proporción considerable de mujeres. Por último, la categoría de dilettanti (c3) incluiría los amateur ocasionales pertenecientes a las clases medias y altas educadas ("Bildungsbürtergum"), con una proporción significativa (puede que incluso una mayoría) de mujeres. Por ejemplo, tanto Mme. Gautier Delessert, la destinataria de las cartas de Rousseau sobre botánica, como la emperatriz Josephine, aseguraron la difusión de libros sobre flores y jardinería, y constituían el público central de diversos cursos sobre botánica. Uno de los rasgos distintivos del siglo XVIII, especialmente en su última época, es precisamente la explosión de botánicos menores y aficionados de todos los tipos.

Por motivos de disponibilidad de datos biográficos, esta contribución se centrará en una élite de botánicos limitada a 928 académicos más o menos comprometidos (ver Tabla 2). Este conjunto está formado en un $80 \%$ por especialistas de los grupos a1 y b1, y de un $20 \%$ de botánicos menos especializados de los grupos a2 y b2. Con tal de incluir los maestros de la primera generación y los discípulos de la última de nuestro conjunto, hemos decidido incluir otro grupo de 81 académicos que ejercieron antes de 1700 o después de 1825. Entre ellos, 28 fueron botánicos, tanto especialistas como no.

\section{La red de maestros y discípulos}

El análisis de redes se ha limitado a una élite de 928 académicos que pertenecen principalmente a las categorías a 1 y b1, y representantes (en un $20 \%$ de los casos) de las amplias categorías a2 y b2, de botánicos no especializados. Hemos considerado que son vínculos de formación todas aquellas relaciones entre estos botánicos y sus maestros o sus discípulos en cualquier campo de investigación, siempre y cuando se trate de científicos que cumplan con los criterios que definen las categorías a o b. 
REDES- Revista hispana para el análisis de redes sociales

Vol.21,\#7, Diciembre 2011

http://revista-redes.rediris.es

En conjunto, la red tiene una densidad muy baja (1\%). Esto se explica por los siguientes hechos: $1^{\circ}$ ) las relaciones de formación están rígidamente estructuradas dentro de un marco cronológico; $2^{\circ}$ ) sólo conciernen a unos pocos individuos; $3^{\circ}$ ) la mayoría de individuos tiene un solo director, mientras que los directores sólo tienen unos cuantos discípulos. La centralización también es baja, con una centralidad de grado de salida de $1,6 \%$ y una centralidad de intermediación del $0,07 \%$. A pesar de la baja densidad y centralidad, la red muestra ciertas estructuras, con áreas de mayor densidad separadas por agujeros.

Con tal de ir más allá de la escasez de vínculos que caracteriza a la red, nos hemos centrado en los individuos que tienen por lo menos una conexión. Entre los 928 botánicos, hay 518 nodos aislados, bien sea porque fueron autodidactas, o porque no hay registro de su educación formal con otro académico que pertenezca a las categorías a $\circ \mathrm{b}^{3}$. Los otros 410 tenían por lo menos un maestro o un discípulo perteneciente a los académicos que hemos identificado con los criterios a y $b$. Entre estos académicos, 81 vivieron bien antes de 1700, bien después de 1830, y de ellos 28 eran botánicos. Por lo tanto, es posible considerar que nuestro conjunto de botánicos interrelacionados es de $438(410+28)$. El $40 \%$ de ellos pertenece a la categoría de académicos destacados (categoría a), y el $60 \%$ a los de segundo rango (categoría b).

Entre estos botánicos conectados, hemos calculado los componentes, es decir, los sub-grafos en los cuales existen conexiones dentro del propio sub-grafo, pero no entre otros sub-grafos. Los componentes dividen la red en partes separadas, en las que hay distintos actores conectados unos con otros (Hannemann y Riddle, 2005). En un componente, cada actor está directa o indirectamente conectado a los demás. En términos substantivos, los componentes débiles capturan conjuntos de académicos que están directa, o más a menudo, indirectamente conectados los unos con los otros por lazos seudo-genealógicos entre maestros y discípulos. En otras palabras, en un componente se interseccionan diversas genealogías de maestros y discípulos a causa de los ancestros o descendientes comunes. En este contexto, los componentes débiles pueden entenderse como grupos dispersos que se desarrollan a lo largo del tiempo. Al centrarnos en los componentes débiles del

\footnotetext{
${ }^{3}$ Hemos excluido muchos vínculos que eran sólo probables, o incluso altamente probables, pero no seguros, así como se han excluido todos los vínculos con aquellos académicos que no figuran en nuestra muestra de científicos claramente identificables. Mejoras en los datos biográficos, así como investigaciones más atentas sobre los currículos universitarios ciertamente hubiera reducido el número de nodos aislados.
} 
REDES- Revista hispana para el análisis de redes sociales

Vol.21,\#7, Diciembre 2011

http://revista-redes.rediris.es

gráfico ${ }^{4}$ observamos que se divide en 66 componentes. El más grande incluye 242 individuos y el segundo mayor sólo a 9 . Por lo tanto, hay un gran número de componentes muy pequeños y de individuos aislados. El componente débil más grande se presenta en la Figura $1^{5}$. Está estructurado cronológicamente, aunque no de modo lineal. En el centro del gráfico están los académicos más antiguos (de finales del siglo XVII), mientras que en los márgenes se encuentran los científicos de finales del siglo XVIII y principios del XIX. La figura muestra que el componente débil más grande se organiza alrededor de un centro densamente conectado.

En una inspección visual notamos que se divide en tres subconjuntos, con relativamente escasas conexiones entre sí: uno aparece en lo alto del gráfico, el otro en el margen inferior izquierdo, y el tercero en el margen inferior derecho. Para evaluar con herramientas analíticas la presencia de subconjuntos en el componente débil más grande, hemos usado el algoritmo Girwan-Newman (Girwan y Newman, 2002), y se han explorado entre dos y diez soluciones por grupos. La solución con tres grupos resultó ser la que mejor se adaptó. Lo que confirma que el componente débil más grande está dividido en tres subconjuntos, que han sido pintados con colores distintos en el gráfico. Los tres subconjuntos tienen un densidad del $2 \%$, mientras que la densidad entre los subconjuntos es muy cercana a 0 .

\footnotetext{
${ }^{4}$ Los componentes débiles no toman en cuenta la dirección de los lazos a diferencia de los componentes fuertes. El identificar componentes permite a los investigadores centrarse en las áreas con conexiones dentro de redes dispersas.

${ }^{5}$ Las figuras se crearon con Pajek (Batagelj y Mrvar, 1998), un software dedicado al análisis de redes grandes. En el caso de los vínculos de formación entre botánicos, hemos usado el logaritmo KamadaKawai.
} 


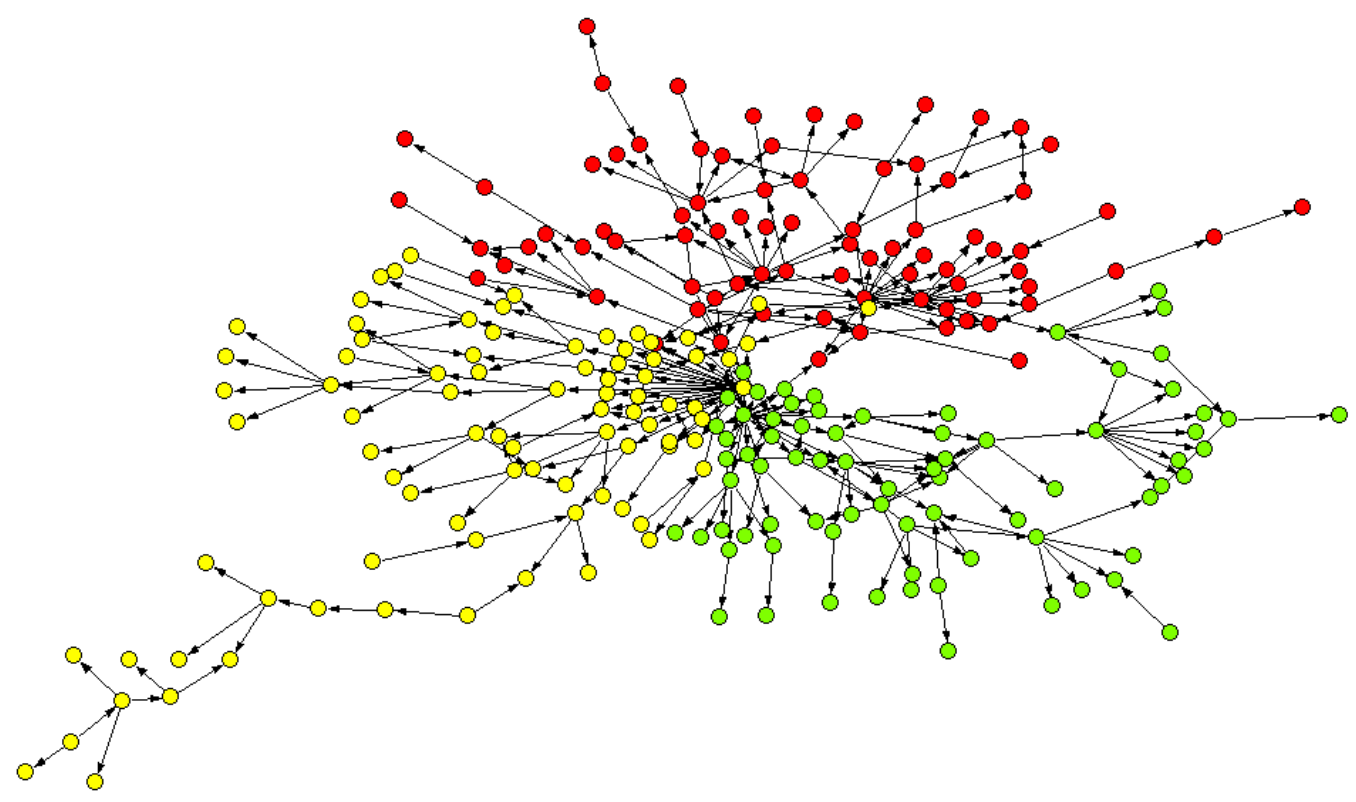

Sub-grupo 2- Verde: Grupo francés
Sub-grupo 3-Rojo: Grupo mixto

Figura 1: Subconjuntos del algoritmo Girwan-Newman aplicado sobre el mayor componente débil ${ }^{6}$

Como se aprecia en la Figura 2, los subconjuntos se asocian a los orígenes nacionales de los científicos. El subconjunto de la parte inferior del gráfico está compuesto principalmente de académicos franceses (en verde), con unos pocos botánicos de origen británico (en rojo) y suizos (en marrón). Está muy densamente conectado. El grupo a la izquierda tiene un tronco sueco (en blanco) que conecta en la parte más externa con muchos alemanes (en amarillo). Las conexiones entre botánicos suecos y alemanes se propagan en tres direcciones distintas. El tercer subconjunto, en la parte derecha del gráfico, es más diverso e incluye una mezcla de alemanes (en amarillo), holandeses (en morado claro) y suizos (en marrón), así como un contingente de académicos franceses (en verde) e ingleses (en rojo). Por lo tanto es mucho más heterogéneo que los otros dos subconjuntos.

\footnotetext{
6 Este gráfico y los siguientes fueron creados con el algoritmo Fruchtermann-Reingold en Pajek (Batagelj \& Mrvar, 1998).
} 
REDES- Revista hispana para el análisis de redes sociales

Vol.21,\#7, Diciembre 2011

http://revista-redes.rediris.es

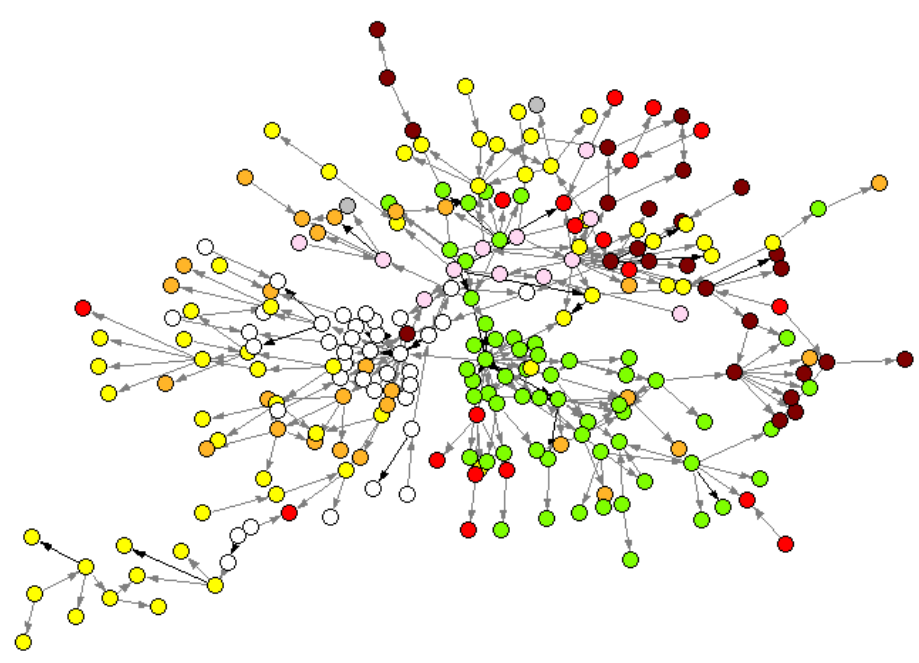

\begin{tabular}{|l|l|l|l|l|l|l|l|}
\hline $\begin{array}{l}\text { Amarillo: } \\
\text { Alemania }\end{array}$ & $\begin{array}{l}\text { Verde: } \\
\text { Francia }\end{array}$ & $\begin{array}{l}\text { Rojo: } \\
\text { Gran Bretaña }\end{array}$ & $\begin{array}{l}\text { Gris: } \\
\text { Italia }\end{array}$ & $\begin{array}{l}\text { Blanco: } \\
\text { Suecia }\end{array}$ & $\begin{array}{l}\text { Marrón: } \\
\text { Suiza }\end{array}$ & $\begin{array}{l}\text { Púrpura: } \\
\text { Países Bajos }\end{array}$ & $\begin{array}{l}\text { Naranja: } \\
\text { Otros }\end{array}$ \\
\hline
\end{tabular}

Figura 2: Componente débil más grande coloreado según país de origen

¿Qué explica la existencia de estos subconjuntos diferenciados? En la Tabla 3 se presentan diversas características de los miembros de los tres subconjuntos, con medidas estándar de asociación. Confirma que los subconjuntos tienen una asociación significativa con el origen "nacional". El primer subconjunto está compuesto principalmente de suecos y alemanes; en el segundo, con 75 individuos, hay mayoritariamente franceses, y en el tercero, con 86 individuos, hay una mezcla de alemanes, holandeses, suizos y otros. 
REDES- Revista hispana para el análisis de redes sociales

Vol.21,\#7, Diciembre 2011

http://revista-redes.rediris.es

\begin{tabular}{|c|c|c|c|c|}
\hline & $\begin{array}{c}\text { Sub-grupo 1- } \\
\text { Amarillo: } \\
\text { Grupo sueco - } \\
\text { germánico }\end{array}$ & $\begin{array}{c}\text { Sub-grupo 2- } \\
\text { Verde: } \\
\text { Grupo francés }\end{array}$ & $\begin{array}{c}\text { Sub-grupo 3- } \\
\text { Rojo: } \\
\text { Grupo mixto }\end{array}$ & $\begin{array}{c}\text { Chi cuadrado } \\
\text { (V de } \\
\text { Chramer) }\end{array}$ \\
\hline País de origen & & & & $216 * *(.67)$ \\
\hline Alemania & 36 & 3 & 32 & \\
\hline Francia & 0 & 65 & 12 & \\
\hline Gran Bretaña, Irlanda & 2 & 11 & 11 & \\
\hline Italia & 0 & 0 & 3 & \\
\hline Países Bajos & 0 & 0 & 15 & \\
\hline Suecia & 44 & 0 & 0 & \\
\hline Suiza & 1 & 15 & 17 & \\
\hline Otros países & 16 & 7 & 10 & \\
\hline Total & $100,00 \%$ & $100,00 \%$ & $100,00 \%$ & \\
\hline Grado de especialización & & & & $16 * *(.18)$ \\
\hline Sólo botánica & 71 & 57 & 53 & \\
\hline Botánica y otras ciencias & 12 & 17 & 30 & \\
\hline Otras ciencias y botánica & 11 & 15 & 16 & \\
\hline Otra ciencia & 7 & 11 & 1 & \\
\hline Total & $100,00 \%$ & $100,00 \%$ & $100,00 \%$ & \\
\hline Importancia & & & & $7 *(.17)$ \\
\hline Académicos "a" & 47 & 56 & 35 & \\
\hline Académicos "b" & 53 & 44 & 65 & \\
\hline Total & $100,00 \%$ & $100,00 \%$ & $100,00 \%$ & \\
\hline $\begin{array}{l}\text { Año de nacimiento (promedio } \\
\text { y desviación estándar) }\end{array}$ & $1757(47)$ & $1752(28)$ & $1701(39)$ & $51 * *$ (F-test) \\
\hline $\begin{array}{l}\text { Año } \quad \text { de } \\
\text { (recodificado) }\end{array}$ & & & & $52 * *(.46)$ \\
\hline Antes de 1740 & 35 & 35 & 84 & \\
\hline 1740 y después & 65 & 65 & 16 & \\
\hline Total & $100,00 \%$ & $100,00 \%$ & $100,00 \%$ & \\
\hline
\end{tabular}

Tabla 3: Características de los tres sub-grupos identificados (\%). 
REDES- Revista hispana para el análisis de redes sociales

Vol.21,\#7, Diciembre 2011

http://revista-redes.rediris.es

Resulta interesante que diversas otras características, además de la nacionalidad, están correlacionadas con la pertenencia a determinado subconjunto. Por ejemplo, los miembros del subconjunto mixto son, en promedio, dos generaciones mayores que aquellos de los subconjuntos francés y sueco-germánico. El subconjunto mixto es más interdisciplinar, e incluye académicos menos prominentes que el subconjunto francés. Este último es ligeramente más multidisciplinar e incluye a académicos más famosos que el subconjunto sueco-germano. En lo que respecta a las naciones, los holandeses y los suecos sólo pertenecen a un subconjunto, mientras que los botánicos alemanes, suizos e incluso los franceses pertenecen a dos subconjuntos diferentes, y los ingleses están repartidos por todos ellos.

La Figura 2 y la Tabla 3 también revelan diferencias importantes en la intensidad de las conexiones de acuerdo con la nacionalidad de origen, y esta característica se muestra consistente tanto si se contempla toda la red $(\mathrm{N}=928+28)$, como el componente débil más grande $(\mathrm{N}=242)$, o los componentes menores y los individuos aislados. De hecho, el $67 \%$ de los botánicos nacidos en Gran Bretaña están aislados, como el $90 \%$ de los nacidos en Italia, en comparación con el $40 \%$ de los suecos y el $38 \%$ de los alemanes. La proporción de nodos aislados es incluso menor en Francia (24\%), en Holanda (19\%) y en Suiza (4\%). No hay una explicación sencilla para estas diferencias, puesto que la existencia de muchas universidades, por sí misma, no garantiza lazos de formación densos (véase el caso de Italia), mientras que los sistemas universitarios mediocres tampoco excluyen altos niveles de conexiones (véanse Francia y Suiza).

\section{Buscando el núcleo: el bicomponente}

¿Hay un subconjunto de individuos especialmente interconectados que constituyan el núcleo de la red dentro del componente débil más grande? Para hallar este núcleo hemos decidido calcular el bicomponente de la red, lo que equivale a un subconjunto de individuos máximamente interconectados sin un vértice de corte (De Nooy, Mrvar y Batagelj, 2005). En un bicomponente nadie puede controlar completamente el flujo de información entre otras dos personas, porque siempre hay un camino alternativo por el que la información podría circular. En otras palabras, en un bicomponente, cada persona recibe información por lo menos desde dos fuentes. En este caso, el sentido de un bicomponente es ligeramente distinto, puesto que la red tiene una profundidad histórica por la que resulta imposible para diversos actores comunicarse directamente entre sí, al haber vivido 
REDES- Revista hispana para el análisis de redes sociales

Vol.21,\#7, Diciembre 2011

http://revista-redes.rediris.es

en épocas distintas. Todos ellos, sin embargo, comparten la propiedad, bien de haber sido formados por dos maestros, bien de haber tenido por lo menos dos discípulos, bien de estar entre dos caminos que unan a un maestro y un discípulo con otros botánicos. Esta situación probablemente supone un vector de influencia científica, que combina la continuidad y el cambio.

Hay 71 académicos en el bicomponente que gráficamente corresponde al centro del mayor componente débil. La Tabla 4 presenta diversas características de los individuos incluidos en el bicomponente y se ponen en comparación con las de los otros miembros del mayor componente débil y de otros individuos que, o bien están aislados, o bien pertenecen a componentes débiles más pequeños.

\begin{tabular}{|c|c|c|c|c|}
\hline & $\begin{array}{l}\text { Miembros del } \\
\text { bicomponente } \\
(71)\end{array}$ & $\begin{array}{l}\text { Otros miembros del } \\
\text { mayor componente } \\
\text { débil (171) }\end{array}$ & $\begin{array}{c}\text { Nodos aislados } \\
(714)\end{array}$ & $\begin{array}{l}\text { Chi cuadrado } \\
\text { (V de Chramer) }\end{array}$ \\
\hline País de origen & & & & $232 * *(.35)$ \\
\hline Alemania & 16 & 28 & 27 & \\
\hline Francia & 41 & 18 & 19 & \\
\hline Gran Bretaña, Irlanda & 3 & 10 & 27 & \\
\hline Italia & 0 & 1 & 10 & \\
\hline Países Bajos & 10 & 3 & 3 & \\
\hline Suecia & 13 & 13 & 17 & \\
\hline Suiza & 14 & 9 & 1 & \\
\hline Estados Unidos & 0 & 0 & 3 & \\
\hline Otros países & 4 & 14 & 10 & \\
\hline Total & $100,00 \%$ & $100,00 \%$ & $100,00 \%$ & \\
\hline $\begin{array}{l}\text { Grado de } \\
\text { especialización }\end{array}$ & & & & $9(.07)$ \\
\hline Sólo botánica & 56 & 63 & 63 & \\
\hline Botánica y otras ciencias & 30 & 15 & 18 & \\
\hline Otras ciencias y botánica & 14 & 21 & 20 & \\
\hline Otra ciencia & $100,00 \%$ & $100,00 \%$ & $100,00 \%$ & \\
\hline Total & & & & $68 * *(.27)$ \\
\hline Importancia & 59 & 40 & 20 & \\
\hline Académicos "a" & 41 & 60 & 80 & \\
\hline Académicos "b" & $100,00 \%$ & $100,00 \%$ & $100,00 \%$ & \\
\hline Total & $1720(39)$ & $1743(48)$ & $1749(47)$ & $12 * *$ (ANOVA) \\
\hline $\begin{array}{l}\text { Año de nacimiento } \\
\text { (promedio y desviación } \\
\text { estándar) }\end{array}$ & & & & $52 * *(.46)$ \\
\hline $\begin{array}{l}\text { Año de nacimiento } \\
\text { (recodificado) }\end{array}$ & 66 & 45 & 36 & \\
\hline Antes de 1740 & 34 & 55 & 64 & \\
\hline 1740 y después & $100,00 \%$ & $100,00 \%$ & $100,00 \%$ & \\
\hline
\end{tabular}


REDES- Revista hispana para el análisis de redes sociales

Vol.21,\#7, Diciembre 2011

http://revista-redes.rediris.es

Tabla 4: Comparación de las características (país de origen, período de nacimiento, importancia científica y grado de especialización) entre los miembros del bicomponente, el resto de miembros del mayor componente débil y el resto de botánicos incluidos en la muestra.

Dentro del bicomponente, los botánicos pertenecen al primer rango $(A)$ con mayor frecuencia que los científicos del resto del componente débil más grande y que entre los otros individuos. Este hecho es perfectamente comprensible si se admite que tener más discípulos es un modo de potenciar la propia reputación científica ( $y$ viceversa) y, por lo tanto, de estar integrado en el núcleo de la disciplina emergente. Estos individuos también tienen fechas de nacimiento más tempranas que los de los otros dos subconjuntos, lo que denota una mayor cohesión de este grupo en un periodo temprano, cuando las principales plazas de formación estaban restringidas a unos pocos centros (Leyden, Ámsterdam, París, Montpellier, Göttingen). La subsiguiente multiplicación de escuelas en Suecia (Uppsala, Lund), Alemania (Leipzig, Berlín, Karlsruhe, Halle) y otras partes (Ginebra, Copenhague), redujo la necesidad de los botánicos de practicar la peregrinatio academica, es decir, asistir a cursos en diversas universidades extranjeras. Como a principios del siglo XVIII la formación botánica a menudo se combinaba con la medicina y otras ciencias, los miembros del bicomponente también muestran algo más de interdisciplinariedad, aunque la diferencia con los otros componentes no es muy grande en este aspecto.

El bicomponente incluye una proporción mucho mayor de franceses, holandeses, suecos e incluso suizos que el componente débil más grande y que el grupo de individuos aislados. La proporción de británicos e italianos, y también de alemanes es mucho menor. Para los franceses y los holandeses, en el bicomponente, se refuerzan las tendencias que ya se observaron en el mayor componente débil, hecho que refuerza el rol crucial que jugaron estas dos naciones en la enseñanza de la botánica, así como de las ciencias naturales y médicas en general (Taton, 1964; de Ridder-Symoens, 1989). La concentración de catedráticos en París y en Leyden podría explicar esta posición privilegiada. Para Suecia y Suiza se confirman las tendencias anteriormente observadas, que muestran el rol crucial de individuos específicos como Linné, pero también Haller durante sus años en Göttingen. De modo interesante, "Alemania" se mantiene en el componente débil, pero retrocede en el bicomponente, mientras que Gran Bretaña retrocede incluso más. 
REDES- Revista hispana para el análisis de redes sociales

Vol.21,\#7, Diciembre 2011

http://revista-redes.rediris.es

\section{Una exploración de los tres subconjuntos}

La información más sorprendente que se ha proporcionado en la sección previa es la existencia de subconjuntos entre los botánicos de primer orden y mejor conectados del siglo XVIII, lo que indica del modo más claro posible la existencia de tres genealogías distintas de botánicos, con características estructurales distintas. Mientras el subconjunto más grande incluye a los individuos con una formación más internacional y menos especializada, nuestra hipótesis de partida sobre una ciencia crecientemente especializada que se desarrolla en un contexto crecientemente nacional gana más relevancia. Sin embargo, la evolución histórica de la formación botánica en el siglo XVIII ni era lineal, ni estaba exenta de paradojas. Para lograr más información sobre el significado de estos tres subconjuntos se debe prestar mayor atención a la composición de cada uno de ellos y registrar las características personales que proporciona el World Biographical Information System (Sistema mundial de información biográfica). En una segunda etapa examinaremos los lazos de formación dentro de las comunidades nacionales de botánicos que no figuran de manera notable en estos tres conjuntos, especialmente el Reino Unido e Italia En estos casos se usarán datos biográficos para establecer las posibles razones de sus posiciones marginales dentro de la red global.

\section{El subconjunto mixto y su núcleo holandés}

Para los miembros del subconjunto mixto (en cuanto a procedencias geográficas), la fecha de nacimiento promedio, situada en 1701, indica que su formación botánica se realizó a principios de la década de 1720, por ejemplo alrededor de 1721. El mismo cálculo nos da 1772 y 1777 como fechas promedio de formación para el subconjunto francés y para el subconjunto sueco-germánico, lo que supone un lapso de medio siglo. Es muy importante tener en cuenta esta diferencia puesto que, entretanto, la comunidad internacional de botánicos había doblado su tamaño: si en 1921 la comunidad de botánicos que cumplía los criterios "a" y "b" era de 96 individuos, entre 1772 y 1777 alcanzó una cifra entre 180 y 190 (Sigrist, 2011). También se doblaron aproximadamente el número de plazas institucionales disponibles durante el mismo periodo. En los siguientes 50 años, el número de botánicos se volvió a doblar, llegando a los 370 en 1825 y lo mismo parece ser cierto para el número de posiciones disponibles. 
REDES- Revista hispana para el análisis de redes sociales

Vol.21,\#7, Diciembre 2011

http://revista-redes.rediris.es

Para el subconjunto mixto, su centro institucional se encontraba en Holanda, aunque un tercio de los botánicos incluidos en él pertenecen a países germánicos del Sacro Imperio. Con 17 discípulos, Hermann Boerhaave (1668-1738) aparece como la figura más central del subconjunto (ver la Figura 3), antes del suizo German Albrecht von Haller (1708-1777) con 12 discípulos y el francés Joseph Pitton de Tournefort (1656-1708) con 11. Hermann Boerhaave, que fue profesor de medicina y botánica en la Universidad de Leyden entre 1709 y 1729, aparece como una figura pivote en el subconjunto, en parte a causa de su posición intermedia cronológicamente, entre Tournefort y Haller. La fecha promedio de formación para los miembros del subconjunto coincide con la cima de su enseñanza en medicina, botánica y química en la Universidad de Leyden. La importancia de Boerhaave como profesor de medicina no tuvo parangón a principios del siglo XVIII en Europa, y muchos de sus estudiantes se convirtieron en figuras punteras, bien en medicina, bien en química (ver los puntos negros en la Figura 3). Algunos de ellos practicaban la botánica como especialidad principal (puntos verdes), o como una especialidad subsidiaria (puntos amarillos). Entre ellos, estuvieron los alemanes Heiser, Trew, Boretius y Buxbaum, los suizos Haller, Gessner, Ammann y Garcin, los británicos Sherard, Alston, Deering y Houston, los holandeses Gronovius, Burman, van Royen y de Haen, y el español Ribeiro Sanches. La influencia de Boerhaave se extendió hasta Austria mediante de Haen y hasta el imperio ruso mediante Ammann y Buxbaum.

\footnotetext{
7 Boerhaave también fue profesor de química entre 1718 y 1729 , y finalmente fue profesor de medicina y de clínica entre 1729 y 1738
} 
REDES- Revista hispana para el análisis de redes sociales

Vol.21,\#7, Diciembre 2011

http://revista-redes.rediris.es

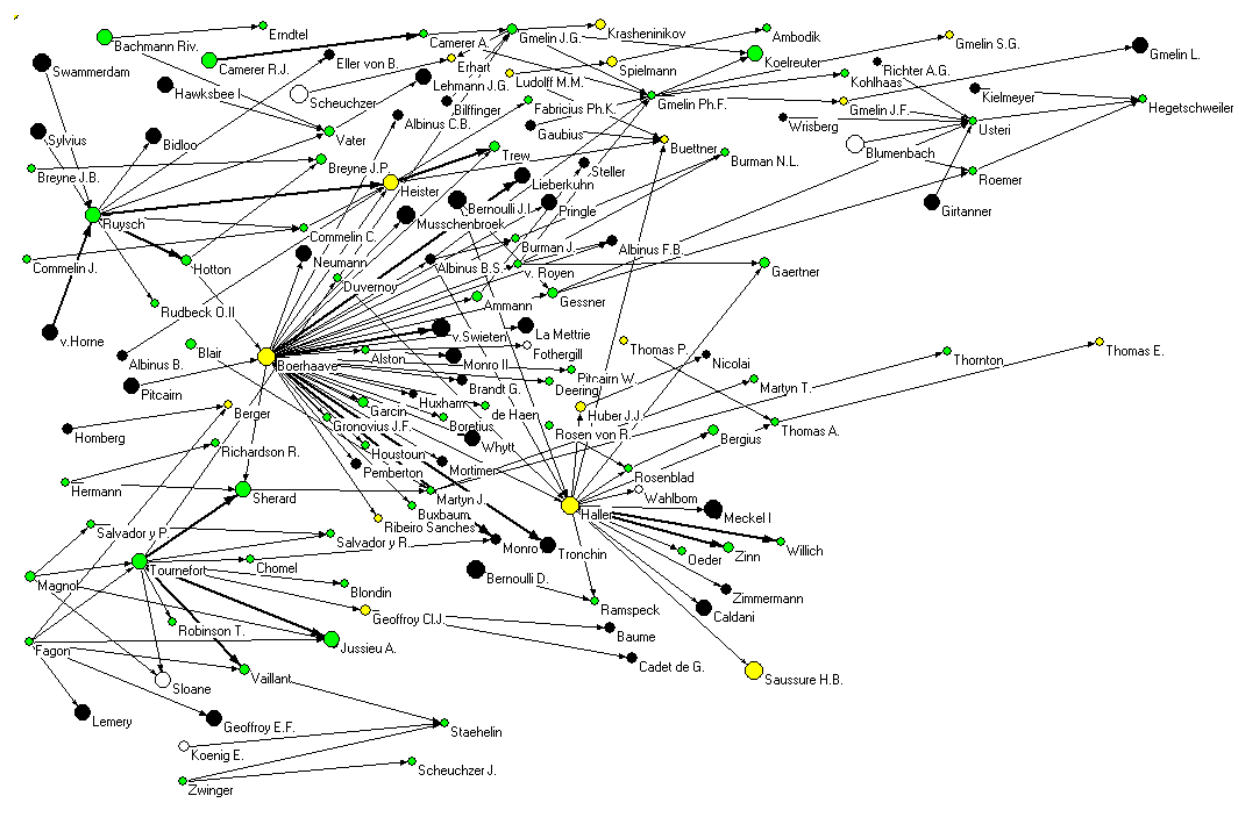

Figura 3: Vínculos de formación dentro del subconjunto mixto. Los botánicos especializados están en verde, los no-especializados en amarillo, los ocasionales en blanco; otros hombres de ciencia están en negro. El tamaño de los vértices es proporcional a la importancia del académico, de acuerdo con criterios formales de filiación académica (0,1,2 o más, entre las seis principales) y la presencia o ausencia en diccionarios biográficos (DBS Macmillan, Gascoigne 1994). Los puntos se distribuyen cronológicamente desde principios del siglo XVII a finales del XVIII.

A principios del siglo XVIII, Boerhaave ejemplifica la tradición de la enseñanza de botánica en las facultades de medicina. Esto sucedía desde mitades del siglo XVI, especialmente en algunas universidades italianas (Boloña, Padua, Pisa), y algo más tarde en la mayoría de institutos en los países alemanes, Francia, Holanda y Suecia. En la mayoría de estas universidades había estudiantes de naciones extranjeras en su peregrination academica junto a los estudiantes locales. Para aquellos que aspiraban a dedicarse a la investigación científica después de su periodo de educación formal, los contactos establecidos con profesores y compañeros a lo largo de sus estudios moldeaban en gran modo su estatus posterior o su posición dentro de la informal "República de las letras y las ciencias".

La posición dominante de Boerhaave también demuestra la importancia dada al conocimiento botánico en los Países Bajos desde su independencia, e incluso antes. Esta importancia tenía que ver con las aplicaciones en la agricultura y los usos comerciales de las plantas, además de sus propiedades médicas. El jardín botánico de Leyden (Hortus academicus), fundado en 1587, ilustraba el largo interés de las 
REDES- Revista hispana para el análisis de redes sociales

Vol.21,\#7, Diciembre 2011

http://revista-redes.rediris.es

Provincias Unidas por nuevas plantas y flores, un interés que simbólicamente culminó en la "crisis de los tulipanes" en 1637. Por lo tanto, las diversas posibilidades de formación que ofrecían algunos jardines botánicos del siglo XVII y principios del XVIII son el resultado de una tradición bien establecida, y lo mismo es cierto para las facultades de medicina holandesas. Paul Hermann, que fue catedrático entre 1696 y 1709, enseñó botánica en la Universidad de Leyden antes que Boerhaav. Había otros bastiones de la botánica en el jardín botánico de Gröningen (fundado en 1641) y en el Hortus medicus de Ámsterdam, fundado en 1684. Su primer responsable, Jean Commelin (1629-1692) empezó una línea brillante de profesores de botánica en el Athenaeum Illustre, que incluían al anatomista Frederik Ruysch (profesor entre 1681 y 1728), el sobrino de Jean Casper Commelin (profesor entre 1706 y 1793), Johannes Burman (profesor entre 1728 y 1779) y su hijo Niklaas Laurens Burman (profesor entre 1780 y 793). Con siete discípulos registrados, sin duda Frederick Ruysch es una de las figuras más centrales de nuestra muestra.

La Figura 3 también muestra el doble estatus, nacional e internacional, de Tournefort. Tournefort fue una figura clave en la conexión y en el establecimiento de una tradición francesa de la clasificación de las especies: primero como estudiante de Magnol en Montpelier y de Guy Fagon en París, y luego como profesor de Sastien Vaillant y de Antoine de Jussieu. También tuvo una dimensión internacional como profesor de William Sherard en Inglaterra y de Johann Georg Duvernoy en Alemania. Este último, a su vez, enseñó a Georg Melin, quien más tarde fue profesor de otros botánicos como Joseph Gottileb Koelreuter, Philip Frederich, Gmelin y el geógrafo y botánico ruso Stephan Krasheninikov.

Para el desarrollo de la botánica como una ciencia de la clasificación de las plantas, la importancia del sistema de Tournefort fue probablemente mucho más decisiva que las enseñanzas de Boerhaave. Sin embargo, una gran parte de su influencia, obviamente, transcurrió a través de otros canales distintos al de la docencia. Por lo que respecta a Haller, que fue profesor en Göttingen entre 1736 y 1753, fue como Boerhaave, una figura puntera en la enseñanza de la medicina, por encima de la botánica. Su lugar eminente en el subconjunto mixto subraya la presencia crucial de botánicos alemanes y suizos. 
REDES- Revista hispana para el análisis de redes sociales

Vol.21,\#7, Diciembre 2011

http://revista-redes.rediris.es

\section{El subconjunto francés}

El segundo subconjunto (en orden cronológico) muestra una homogeneidad nacional sorprendente con un $65 \%$ de botánicos franceses y un $15 \%$ de suizos francófonos, de hecho, ciudadanos de Ginebra como Candolle, que pasó toda la era napoleónica bajo mando francés. Este carácter nacional, en agudo contraste con el reclutamiento internacional del subconjunto mixto, está reforzado por las densas interconexiones entre sus miembros (Figura 4). Sin embargo, la estructura de este subconjunto necesita un examen más detallado antes de concluir la existencia de una comunidad nacional de botánicos en Francia a finales del siglo XVII y principios del XIX.

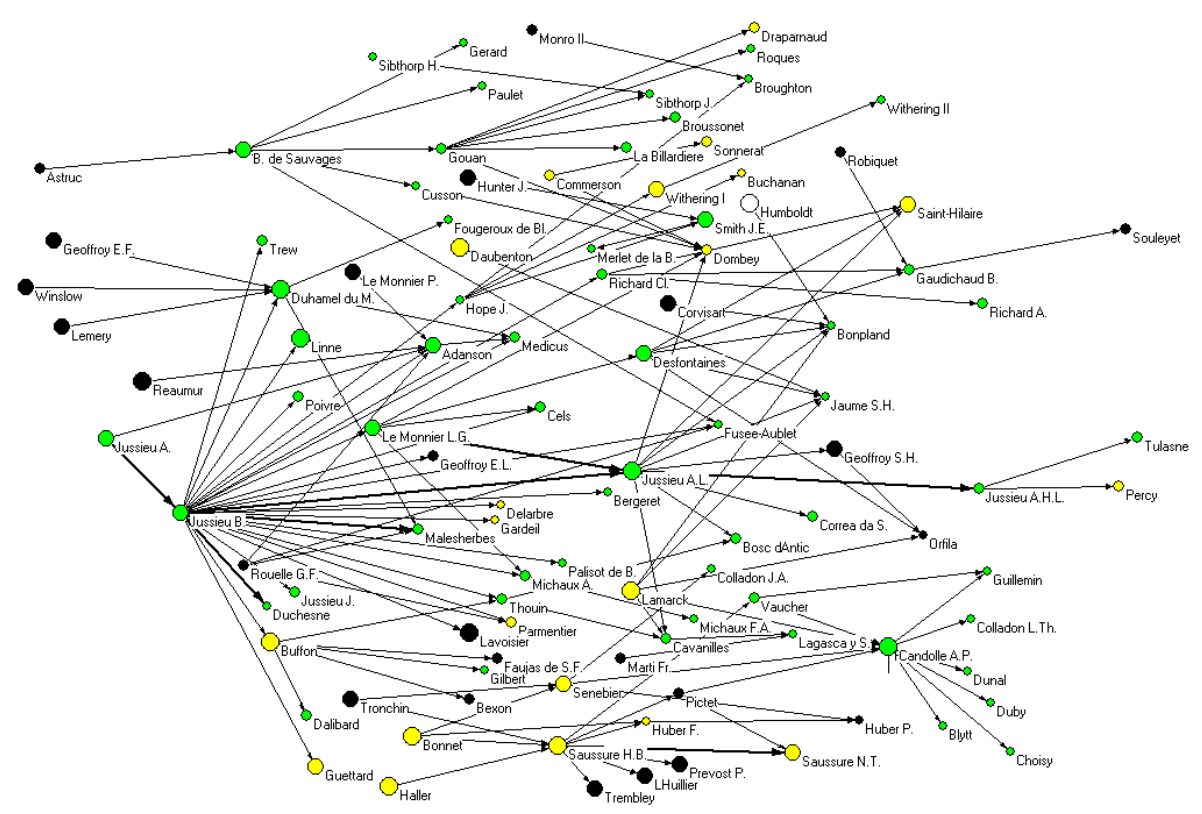

Figura 4: Vínculos de formación dentro del subconjunto francés. Los nodos se ubican cronológicamente desde mediados del s. XVII a principios del XIX.

A juzgar por el número de discípulos, la comunidad francesa de botánicos del siglo XVIII está dominada por la dinastía Jussieu, especialmente por Bernard (con 27 discípulos) y por Antoine-Laurent (con 8), y en menor grado por Antoine (con 4). Entre otros profesores y maestros notables se incluyen Louis-Guillaume Le Monnier (5 discípulos) y Lanmarck (con 5) en París, François Boissier de Sauvages (con 5) y Antoine Gouan (con 7) en Montpellier, así como Augustin Pyramus de Candolle (7) en Montpellier y Ginebra. Por lo tanto, el dominio de París, que se concentraba en el Jardin du Roi, la Académie de Sciences y el jardín de Trianon en Versalles, no era 
REDES- Revista hispana para el análisis de redes sociales

Vol.21,\#7, Diciembre 2011

http://revista-redes.rediris.es

exclusivo. Hasta finales del siglo XVII, el jardín de la facultad de medicina de Montpellier, fundado en $1597^{8}$, estaba en posición de disputarse la supremacía con el Jardin du Roi en París, fundado en el $1635^{9}$. Fue en Montpellier donde Magnol hizo el primer intento de clasificación de las plantas. También fue en Montpellier donde Tournefort estudió por primera vez, bajo Magnol, y antes de convertirse en el alumno de Fagon en París. El mismo camino de Montpellier a París lo siguió Antoine de Jussieu, antes de enseñar botánica en el Jardin du Roi (1710-1758).

A principios del siglo XVIII el desarrollo de una tradición botánica francesa se benefició de la publicación del sistema clasificatorio de Tournefort (1694) y la demostración de la sexualidad de las plantas por parte de Vaillant (1717) (Williams, 2001). El Jardin du Roi, la Académie de Sciences y otras instituciones menores permitieron la concentración de especialistas en París, sin parangón en cualquier otra parte. Tras la muerte de Antoine de Jussieu (1758), Louis-Guillaume Le Monnier enseñó botánica en el Jardin du Roi, pero fue Bernard de Jussieu (16991777), dirigente del jardín de Trianon, quien enseñó a los estudiantes más famosos, entre ellos, Le Monnier, Buffon, Adansonn, Guettard, Duhame du Monceau, Thouin, Claude Richard, Antoine Richard, así como su propio sobrino Antoine-Laurent de Jessieu. También fue en el jardín de Trianon de Versalles donde Bernard de Jussieu, con la ayuda del jardinero Claude Richard, desarrolló su clasificación de las plantas por primera vez. Esta clasificación, basada en la anatomía de las plantas y en una jerarquía de caracteres, después sería aplicada al Jardin du Roi de la mano de Antoine-Laurent de Jussieu (1774), antes de que él publicara sus principios en Genera Plantarum (1789). Esto representará un hito sobre una nueva escuela de botánica, introducida por Candolle en Suiza, por Robert Brown en Reino Unido, por Kunth en Alemania y por Cavanilles en España.

\footnotetext{
${ }^{8}$ El decreto real se promulgó en 1593

${ }^{9}$ El decreto real fue promulgado en 1620, y la apertura oficial sucedió en 1640
} 
REDES- Revista hispana para el análisis de redes sociales

Vol.21,\#7, Diciembre 2011

http://revista-redes.rediris.es

En cualquier caso, las instituciones educativas y los desarrollos intelectuales en la botánica raramente tenían un carácter nacional, incluso en Francia. De hecho, los principales botánicos de Montpellier (Boissier de Sauvages, Gouan, Broussonet, La Billardière) ignoraban la clasificación natural de plantas de Jussieu hasta que fue introducida por Candolle después de 1808. En Ginebra, la tradición botánica local consistía principalmente en la fisiología vegetal ilustrada por Bonnet, Senebier y Saussure el hijo, hasta que el retorno de Candolle en 1816 promovió una escuela local de taxonomía natural. En las otras provincias francesas, la tradición de Linné sería la dominante durante mucho tiempo (Duris, 1993), como lo era en muchos otros países fuera de Francia.

\section{El subconjunto sueco-germánico}

El tercer subconjunto, cuyos miembros son bastante contemporáneos de los del subconjunto francés, está centrado claramente sobre la figura de Linné, cuyo número de discípulos alcanza los 31 . El hecho de que Linné fuera profesor de medicina y de botánica en la universidad de Uppsala entre 1742 y 1776 sugiere muchos paralelismos con la carrera de Boerhaave en Leyden. Sin embargo, la separación entre la medicina y la botánica adquirió entretanto cierta consistencia. Linné mismo no heredó una tradición botánica nacional tan fuerte como la holandesa antes de Boerhaave, aunque tuvo algunos predecesores suecos como Olof Celsius u Olof Rudbeck padre e hijo. De hecho, el sistema de clasificación sexual de Linné fue desarrollado en un período de mucho interés por las ciencias aplicadas, promovido desde 1739-41 por la Academia Sueca de las Ciencias (Frängsmyr, 1989). Para aquel entonces, el principal objetivo de la botánica ya había cambiado desde el conocimiento de las plantas medicinales la identificación y clasificación de las especies de todos los orígenes, a menudo con sus usos económicos en mente (Fries, 1950). A causa de esta atención prestada a la clasificación, la historia natural se había convertido en la ciencia más próxima a la botánica, relevando a la medicina. Por lo tanto, gran parte de los alumnos más destacados de Linné eran botánicos o naturalistas en vez de anatomistas, facultativos o patologistas (Figura 5). Si consideramos a los más renombrados, dos tercios se pueden considerar como botánicos especializados (Forsskal, Joerlin, Loefling, Rolander, Lidbeck, Martin, Alströmer, Afzelius, Hellenius, Acharius, Bergius, Thunberg, Dryander, Murray), y el otro tercio como naturalistas (Kalm, Hasselquist, Osbeck, Ascanius, Wahlbom, Montin, Solander). Otra diferencia respecto a Boerhaave es que las investigaciones de Linné estaban enmarcadas en 
REDES- Revista hispana para el análisis de redes sociales

Vol.21,\#7, Diciembre 2011

http://revista-redes.rediris.es

un contexto nacional, por lo que la mayoría de sus discípulos eran suecos, o por lo menos escandinavos. En comparación con el subconjunto francés, sus discípulos tendían más a pertenecer al segundo rango. Sin embargo, considerando todo el subconjunto, la proporción de botánicos especializados era mayor que en el subconjunto francés.

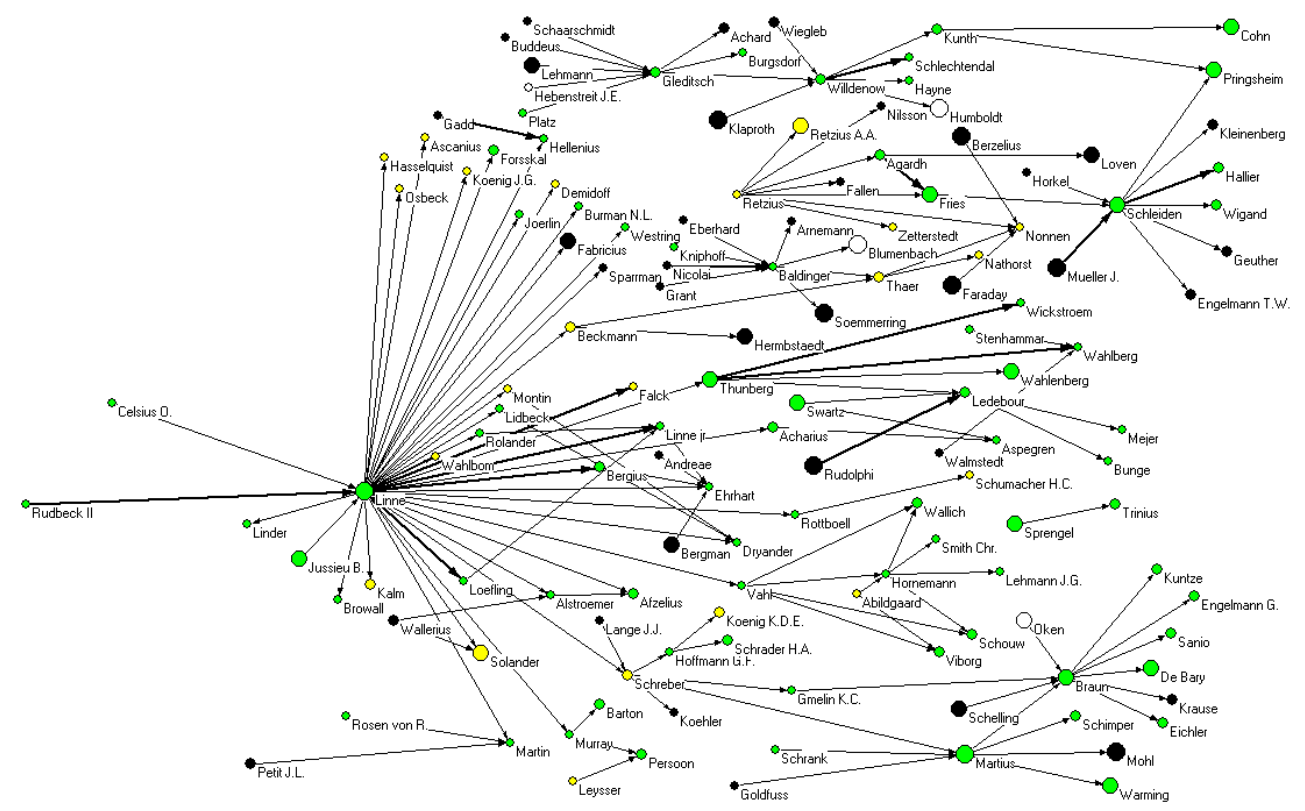

Figura 5: Lazos de formación dentro del subconjunto sueco-germánico. Los puntos se sitúan en orden cronológico desde finales del siglo XVII a mediados del siglo XIX.

Finalmente, la densidad de las interconexiones muestra otra característica interesante. Mientras que la densidad es alta entre los botánicos suecos alrededor de Linné, y hasta cierto punto alrededor de su discípulo Thunberg (quien tuvo seis discípulos), las conexiones son menos frecuentes entre los actores del resto del subgrupo, ya sean alemanes o daneses. En la figura 5 se aprecia que los botánicos alemanes del subconjunto se esparcen por lo menos en tres direcciones distintas: una cuarta pasa por Dane Martin Vahl, quien tuvo cuatro discípulos propios.

Uno de los retoños de Linné en Alemania tenía un carácter principalmente sueco. Primero pasó por Thunberg, sucesor del hijo de Linné en la cátedra de medicina y botánica en Uppsala, quien formó a Karl Friedrich Ledebour (1785-1851) así como a botánicos suecos como Wahlenberg, Wickström y Whalberg. Ledebour, quien dirigía el jardín botánico de Greifswald, en la Pomerania sueca, nació en Greifswald, donde la difusión de la tradición linneana se benefició de un contexto cultural específico (Önnerfors, 2008). Posteriormente, se fue a Dorpat, donde enseñaba historia natural a estudiantes rusos y bálticos como Karl Andreevic Mejer y Alexander von Bunge. 
REDES- Revista hispana para el análisis de redes sociales

Vol.21,\#7, Diciembre 2011

http://revista-redes.rediris.es

La segunda y más importante filiación linneana en Alemania pasó por Johann Christian von Schreber (1739-1810), quien enseñaba botánica y medicina en la Universidad de Erlangen (Bavaria). Vale la pena mencionar a tres de sus estudiantes como ejemplos de los diferentes destinos de la escuela linneana en Alemania. Uno de ellos es Karl Christian Gmelin (1762-1837), quien enseñó botánica en el Gymnasium de Karlsruhe y se mantuvo en la línea clásica de Linné. El segundo, Georg Franz Hoffmann (1766-1826) enseñó botánica en Göttingen (a Heinrich Adolf Schrader, Karl Dietrich Koeing, y también a Goethe y a Humboldt), y más tarde en Moscú. Como especialista en criptogramas, se mantuvo en la misma posición y por lo tanto no puede ser considerado como un verdadero linneano. Como profesor de botánica en Munich, enseñó a Karl Friederich Schimper, morfologista y padre fundador de la filotaxis, así como Alexander Carl Braun, quien se convertiría en el principal representante alemán de la Naturphilosophie en el campo de la botánica.

Un tercer descendiente de la línea alemana de Linné, todavía menos ortodoxo, fue Johann Beckmann (1739-1811), quien enseñó economía y dirigió un jardín agrónomo en Göttingen. Su discípulo más famoso fue el agrónomo Albrecht Daniel Thaer, quien estableció su propio instituto de ciencias agrarias en Möglin, cerca de Potsdam.

El ejemplo de la descendencia de Linné en Alemania ilustra el hecho, ya señalado en el bicomponente, de que los individuos de cada generación están expuestos a influencias cruzadas, las cuales producen nuevas combinaciones de ideas $y$ aseguran la continua reinterpretación de cualquier tradición científica. En el caso alemán, las distintas interpretaciones de Linné pueden haber sido reforzadas por la multiplicidad de centros botánicos. En cualquier caso, los elementos más originales del sistema sexual de Linné fueron tan transformados a finales del siglo XVIII y principios del XIX que apenas se podían reconocer entre su tercera generación de discípulos.

\section{Interpretación de las características observadas}

La distribución de las relaciones entre maestros y discípulos dentro de los subconjuntos definidos anteriormente muestra el predominio de unas pocas instituciones como la puerta de entrada al campo de la botánica, y el rol de estas instituciones en la génesis de comunidades nacionales de botánicos, o por lo menos, en la agregación de núcleos de especialistas autóctonos. Dentro del subconjunto francés, el Jardin du Roi atrajo a la mayoría de futuros botánicos 
REDES- Revista hispana para el análisis de redes sociales

Vol.21,\#7, Diciembre 2011

http://revista-redes.rediris.es

franceses de alguna importancia, sin elegirlos entre estudiantes extranjeros. Lo mismo podría decirse de la facultad de medicina de Uppsala dentro del subconjunto sueco germánico, aunque los discípulos de Linné no eran exclusivamente suecos o súbditos del imperio sueco, sino que también incluye una proporción significativa de alemanes y de daneses. En lo que respecta a los botánicos holandeses, todos pertenecen al subconjunto mixto, pero sólo una minoría de los botánicos reputados fue formada en Leyden. La consideración de las relaciones maestro-discípulo en otros contextos "nacionales" (como Gran Bretaña, "Italia", "Alemania", Suiza) muestra por lo menos dos elecciones posibles. La primera es el impacto mediocre de las instituciones inglesas e italianas en la formación de los botánicos europeos, y el aparente aislamiento de los especialistas insulares y peninsulares. La segunda es la gran variedad de lugares para la formación de los que disponían en su propio país o en el extranjero.

Tras una investigación de estos contextos nacionales concretos nos referiremos a las diferencias de los tres subconjuntos principales para enmarcar una explicación de las tendencias dinámicas que han moldeado la evolución de la botánica entre 1670 y 1830 . Se considerarán como indicadores de las tendencias a largo plazo y también como posibles explicaciones de las variaciones observados en los cambios en las cualificaciones de todo el conjunto de botánicos, y sus elecciones de nuevos lugares de formación y nuevos métodos.

\section{El aislamiento de los botánicos ingleses e italianos}

Desde el punto de vista de los vínculos de formación registrados, la mayoría de los botánicos ingleses del siglo XVIII aparecen aislados, si bien algunos están presentes en el subconjunto mixto así como en el subconjunto francés. Al tomarlos por separado, los botánicos ingleses dan la imagen de una comunidad dispersa con muy pocas interconexiones (Figura 6). Esta imagen de una comunidad "dispersa" tiene diversas explicaciones. La más obvia es la escasez de catedráticos en botánica: sólo 12 de ellos entre todo el periodo de 1700 a 1830 figuran en nuestro conjunto británico, a diferencia de los 14 catedráticos en botánica franceses (la mayoría de ellos en Montpellier y otras ciudades provincianas), los 24 de Italia y los 38 de Alemania. Entre los catedráticos ingleses en medicina, sólo tres serán botánicos ( $y$ ninguno de ellos dirigió un jardín botánico) en comparación a seis en Francia, seis en Italia y 34 en Alemania. En las universidades inglesas el conjunto de la formación médica era bastante pobre. Esta pobreza estaba compensada en buena parte por la formación que ofrecían los hospitales de Londres, pero esto es 
REDES- Revista hispana para el análisis de redes sociales

Vol.21,\#7, Diciembre 2011

http://revista-redes.rediris.es

menos cierto en el campo específico de la botánica. A nivel universitario, el profesor en botánica de Cambridge Richard Bradley (quien enseñó entre 1724 y 1732), así como sus sucesores John Martyn (profesor entre 1733 y 1761) y Thomas Martyn (profesor entre 1761 y 1825), permanecieron a la sombra de sus colegas en las ciencias físico-matemáticas (Gascoigne, 2002). Tras unos pocos años de éxito mediocre abandonaron la docencia. En Oxford, el brillante legado de Johann Jacob Dillenius (profesor entre 1734 y 1747) fue derrochado por Humphrey Sibthorp, quien enseñó una sola vez en casi 40 años (1747-1783), así como su hijo John Sibthorp, que no formó a ningún discípulo con reconocimiento en sus 12 años como profesor (1784-1796). En Edimburgo, donde los docentes en medicina disfrutaban de una amplia reputación internacional, la enseñanza de la medicina tenía una relación más estrecha con la fisiología y la química que con la botánica. La modestia de sus sucesivos profesores en botánica (Charles Alston, John Hope, Daniel Rutherford) podría ser parcialmente responsable de estos hechos, si bien John Hope (profesor entre 1760 y 1786) pudo llamar la atención de estudiantes locales y extranjeros. Él figura en nuestra red con cuatro discípulos.

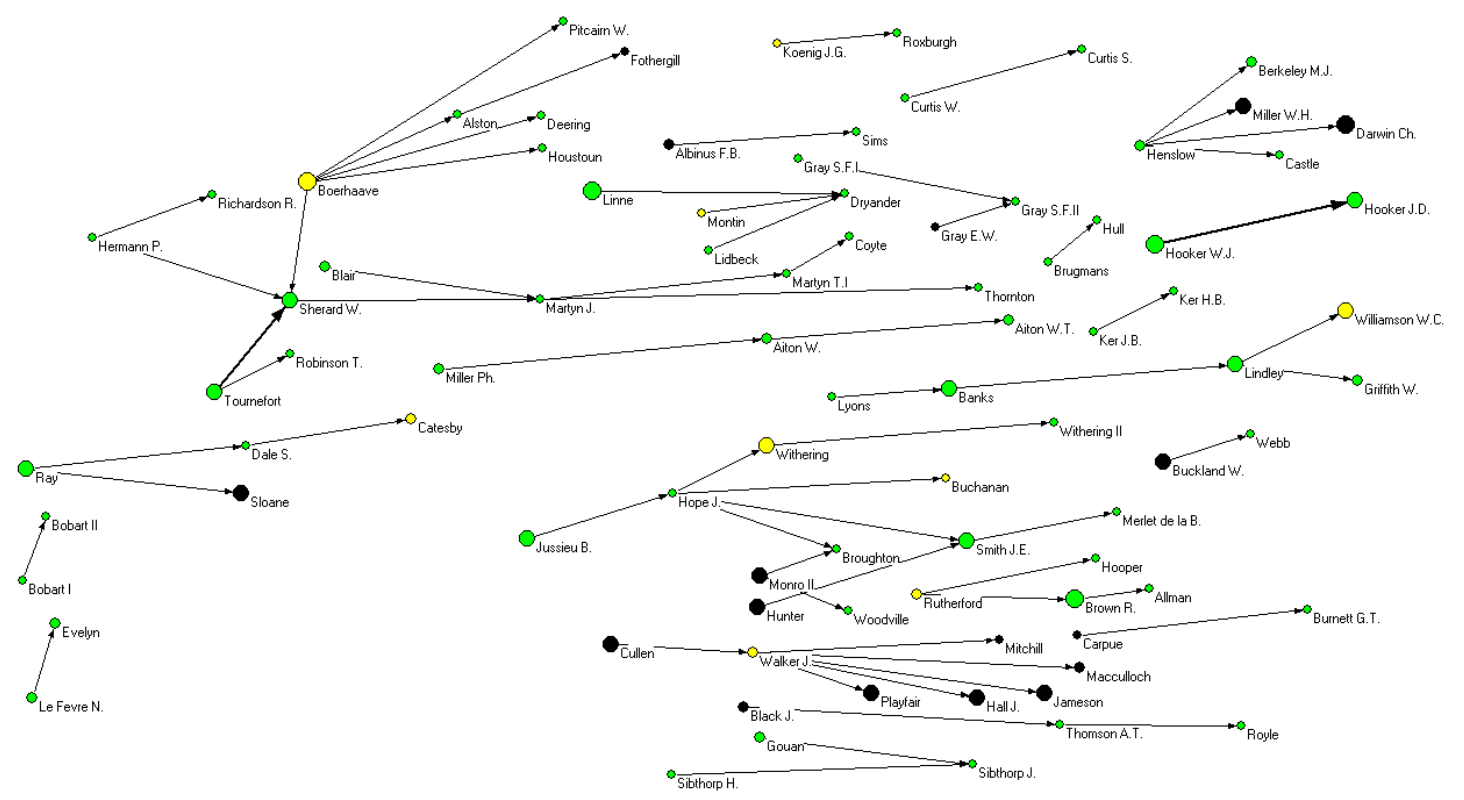

Figura 6: Lazos de formación entre los principales botánicos ingleses. Los puntos se sitúan cronológicamente desde principios del siglo XVII a principios del siglo XIX.

Por otra parte, una importante proporción de los botánicos ingleses, especialmente los más privilegiados, se formaron en universidades extranjeras. Algunos también usaron las instalaciones educativas de los jardines Chelsea Physic (fundados en 1673) y los jardines Kew (fundados en 1760). Por otra parte, podríamos hallar otra explicación a la escasez de vínculos de formación entre botánicos ingleses en la 
REDES- Revista hispana para el análisis de redes sociales

Vol.21,\#7, Diciembre 2011

http://revista-redes.rediris.es

amplia proporción de caballeros eclesiásticos y granjeros que vivían en zonas rurales y que, por lo tanto, no estaban en posición de tutorizar a estudiantes ni discípulos. En nuestra muestra, la proporción de especialistas en plantas que vivían de sus propiedades, rentas o ingresos eclesiásticos alcanza el 23\% (como mínimo), una proporción elevada en comparación a Italia (14\%), Francia, Alemania y otros países (entre el 7 y el $8 \%$ ) ${ }^{10}$. Otra figura típica de la botánica inglesa del siglo XVIII es la gran cantidad de jardineros ilustrados como John Evelyn, Thomas Knowlton, James Lee, James Dickinso,Archibald Menzies, James Forbes, Robert Sweet, John Loudon, George Sinclair, William Baxter, George Don, John Smith, Joseph Paxton, y por supuesto, William y William Townsted Aiton. Prácticamente todos ellos estaban aislados en términos de formación reglada. Unos pocos son testigos de los lazos entre la botánica inglesa y la emergencia del imperio.

El caso italiano se caracteriza por una escasez incluso mayor de lazos en la formación. Los botánicos italianos están prácticamente ausentes del principal componente débil y sus distintos conjuntos. Una explicación posible es el pobre estado de la información biográfica disponible en el WBIS, ya que la proporción de catedráticos de botánica era mucho mayor en Italia (49\% de nuestra muestra) que en Francia (15\%) o Inglaterra (9\%). Era incluso mayor que en Alemania (25\%) y que en otros países como Suecia, Holanda, Suiza, Rusia o los Estados Unidos (con una media del 24\%). Sin embargo la explicación ofrecida por la historiografía es sólo parcial, ya que las facultades de medicina y de filosofía italianas tenían evidentes dificultades para atraer a estudiantes europeos en botánica. La existencia de una cátedra específica en botánica ( $y$ a menudo de agricultura) en varias universidades italianas no era una garantía de una formación en botánica de alto nivel. De hecho, la mayoría de las cátedras eran de reciente creación a principios del siglo XIX, y ayudó a que se incrementara de nuevo el número de botánicos transalpinos, tras un largo período de silencioso declive. Varios de sus nuevos catedráticos tenían un carácter práctico y fuerte, en contraste con la situación atrasada de la agricultura italiana. Los jardines botánicos más antiguos, asociados a las facultades de medicina de Pisa, Padova, Bolonia y Florencia perdieron mucho de su tradicional atractivo. En el siglo XVIII, ya había pasado el tiempo cuando los botánicos europeos fueron a Italia para redescubrir los antiguos libros de Thophrastreus, Pliny y Discorides, o para participar en el Renacimiento de la

\footnotetext{
${ }^{10}$ Sin embargo sería posible que al incluir a los ingenieros agrónomos se aumentará la proporción de caballeros granjeros en Francia, Italia y también otros países
} 
REDES- Revista hispana para el análisis de redes sociales

Vol.21,\#7, Diciembre 2011

http://revista-redes.rediris.es

historia natural al lado de Aldrovandi, Calcolari y Cesalpino. En lugares como Bolonia, Pisa o Florencia, la botánica provinciana era todavía reproductiva pero los académicos transalpinos, obsesionados con su disputa por la supremacía regional o nacional, tendían a perder de vista a sus homólogos europeos.

\section{Los múltiples centros de la botánica alemana y la evolución de tradiciones}

Si el provincianismo parece una característica importante de las comunidades de botánicos italianos, ¿cuál es la situación dentro de los estados alemanes del Sacro Imperio? La docencia en botánica obviamente se beneficiaba de la existencia de un denso sistema universitario que a menudo asociaba las cátedras en medicina con la gestión de un jardín botánico. A pesar de la fragmentación política, los estudiantes alemanes de medicina estaban frecuentemente inscritos en dos, tres o incluso cuatro universidades simultáneamente. Esta actitud, apenas conocida entre los estudiantes italianos, contribuyó a bajar las barreras entre los facultativos y los académicos pertenecientes a distintos estados germánicos. Los aspirantes alemanes a botánico no dudaban por un momento en irse a estudiar al extranjero, de modo que antes de 1780, su presencia en los pasillos universitarios de Leyden y Uppsala era casi tan frecuente como en las facultades de medicina de Göttingen o Leipzig, en el Collegio Medico-Chirurgicam de Berlín o en el Gymnasium de Karlsruhe. Su presencia en el subconjunto mixto y en su conjunto sueco no necesita mayor explicación.

El gráfico de los lazos de formación entre botánicos alemanes confirma la existencia de diversos centros diferentes en el aprendizaje de la botánica, así como la importancia de un puñado de académicos como Albrecht von Haller en Göttingen (12 discípulos), Anton Wilhelm Platz en Leipzig (siete discípulos) y Karl Ludwig Wildenow en Berlín (cuatro discípulos) (Figura 7). Hasta cierto punto, estos centros tenían ciertas diferencias en su orientación científica, a pesar de que la migración de estudiantes y profesores tendía a reducir esas diferencias. Además, es interesante considerar cuál fue el significado de incluir a algunos individuos suecos en su conjunto y como las enseñanzas de Linné fueron interpretadas en diversos contextos locales. 


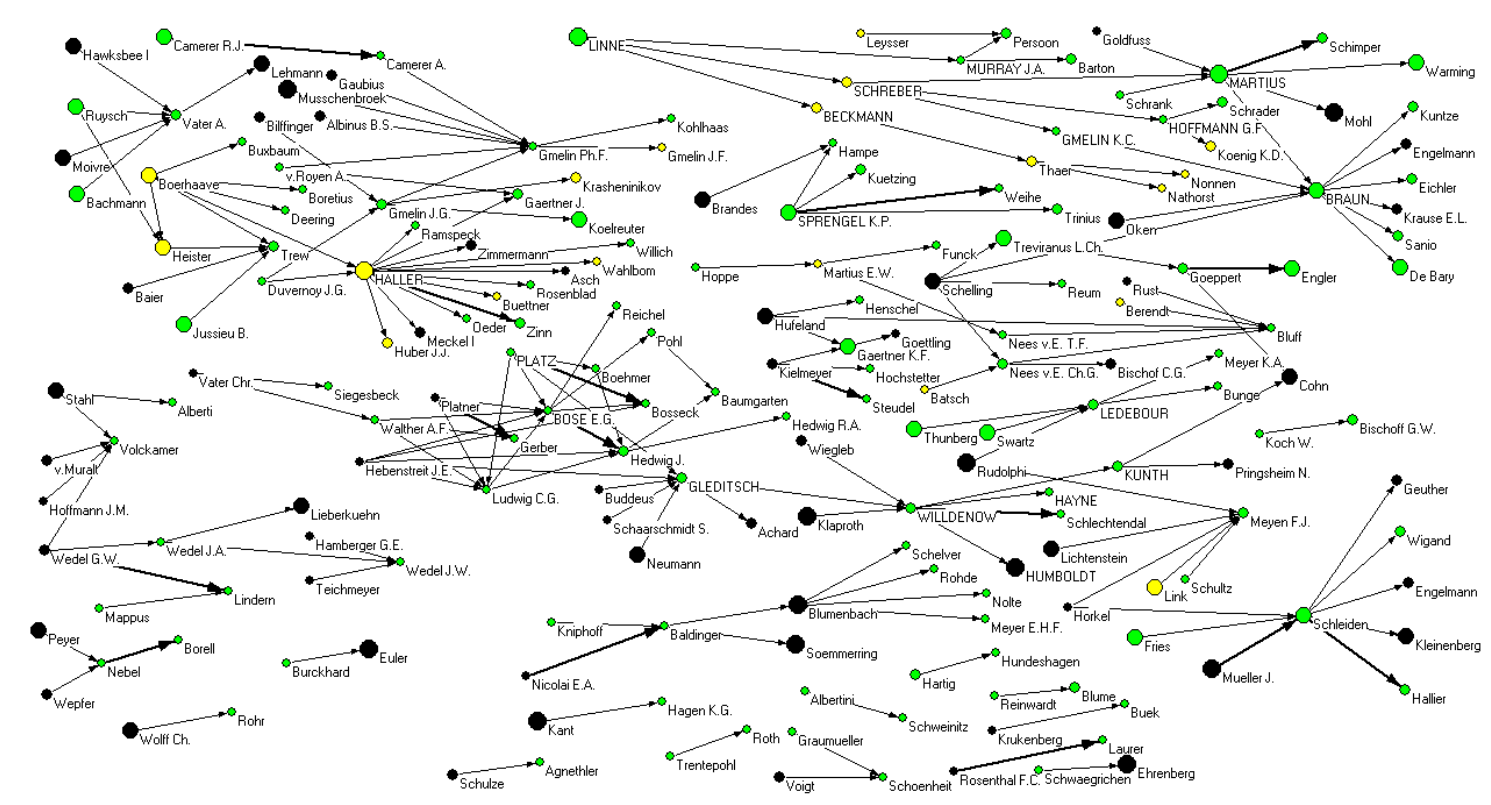

Figura 7: Lazos de formación entre los principales botánicos alemanes. Los puntos están situados en orden cronológico desde mediados del siglo XVII hasta mediados del siglo XIX.

Gracias a Abrecht von Haller, quien creó el jardín botánico de la facultad de medicina de la Universidad de Göttingen (1737), la facultad rápidamente se convirtió en el centro de formación en botánica en la tradición médica de Boerhaave. En el último tercio del siglo XVIII, se había convertido en un bastión del linneismo, enseñado entre 1769 y 1791 por el discípulo de Linné Johan Christian von Scherber en Erlangen. Sin embargo, los discípulos de mayor reputación de Murray, no eran alemanes, sino el holandés Christiaan Hendrik Persoon y el influyente americano Benjamin Smith Barton (quien tiene ocho discípulos dentro de nuestro conjunto). En lo que respecta al Johann Beckmann, otro de los discípulos de Linné asentado en Göttingen, fue profesor de economía entre 1770 y 1811, por lo que su legado intelectual fue transmitido principalmente a agrónomos como Albrecht Daniel Thaer, y químicos como Sigismund Hermbstaedt.

Entre 1770 y 1810 la influencia de Göttingen como centro genuino de la tradición de Linné en Alemania fue disputada por Erlangen, donde el discípulo de Linné Johann Christian Schreber formó al anteriormente citado Georg Franz Hoffmann (posteriormente profesor en Göttingen), así como a Karl Christian Gmelin (posteriormente profesor en Karlsruhe) y Karl Friedrich von Martius (posteriormente profesor en Munich). 
REDES- Revista hispana para el análisis de redes sociales

Vol.21,\#7, Diciembre 2011

http://revista-redes.rediris.es

Leipzig era otro bastión de la tradición botánica-médica desde tiempos de Anton Wilhelm Platz, quien enseñó botánica entre 1733 y 1754, y medicina entre 1754 y 1784. Sus sucesores como profesores de botánica fueron Ernst Gottlob Bose (entre 1754 y 1773), Johann Ehrenfried Pohl (entre 1773 y 1788), ambos de los cuales tenían una formación médica y más tarde fueron profesores de medicina. Por el contrario, Johann Hedwig enseñó primero medicina (entre 1786 y 1788) y después botánica (1788-1799), invirtiendo la jerarquía tradicional de las cátedras académicas.

También en Halle la botánica estuvo a la sombra de la medicina hasta 1795, cuando Kurt Polycarp Sprengel fue nombrado profesor de botánica y director del jardín botánico.

El sistema de clasificación sexual de las plantas de Linné se introdujo en Berlín en 1746 de la mano de Johann Gottlieb Gleditsch (1714-1786), un antiguo estudiante de Platz en Leipzig quien, sin embargo, no tuvo contacto directo con el maestro sueco. Su discípulo Karl Ludwig Willdenow (1764-1812) reformuló la clasificación ya obsoleta de Linné en su obra Grundriss der Kräuterkunde (1792) antes de ser nombrado uno de los sucesores de Gleditsch como director del jardín botánico de Berlín (1801-1812). Después de la fundación de la Universidad de Berlín en 1810, tres de los estudiantes de Willdenow fueron llamados para enseñar botánica en la capital. El primero, Friedrich Hayne (1763-1832), enseñó el modelo de Linné modificado por su maestro entre 1814 y 1829. El segundo, Karl Sigismund Kunth (1788-1850), que hizo de Berlín el principal centro de la botánica alemana, introdujo la clasificación natural de las plantas después de 1829. El tercero, Carl Alexnder Braun (1805-1877), quien enseñó durante muchos años en Karlsruhe y en Freiburg, fue conocido como un partidario de la Naturphilosophie.

Esta breve panorámica intelectual sobre el destino del linneismo en Alemania muestra que, si bien no hay duda de que las relaciones entre maestros y discípulos condicionan la entrada a la "República de los botánicos", no se puede decir que determinen la evolución intelectual de sus miembros. Las influencias intelectuales, que obviamente fluyen por múltiples canales (publicaciones, traducciones, intercambios mutuos), producen nuevas combinaciones en cada generación, transformando continuamente los contornos de cualquier escuela de pensamiento. 
REDES- Revista hispana para el análisis de redes sociales

Vol.21,\#7, Diciembre 2011

http://revista-redes.rediris.es

\section{Contrastes entre las características de los 3 subconjuntos}

Los casos de Gran Bretaña, Italia y Alemania dan información acerca de la semiperiferia de la "República de los botánicos" del siglo XVIII; las características de los 3 subconjuntos que dominaron las relaciones entre maestros y discípulos permiten identificar los cambios que afectaron al núcleo durante ese mismo período, especialmente en las 5 o 6 décadas entre el cenit del subgrupo mixto (entre 1710 y 1720) y el apogeo de los grupos franceses y sueco (en la década de 1770).

Una formación de alto nivel en botánica entre los miembros del subconjunto mixto, a menudo significó desplazarse a grandes distancias entre fronteras nacionales o lingüísticas. La entrada en las redes de la "República de las letras" también estaba condicionada a la tradicional práctica de peregrinatio academica. Una mirada más atenta a la estructura de este subconjunto mixto muestra que está subdividido en 3 - 4 subgrupos dominados por las figuras de Boerhaave, Haller, Tournefort y Ruysch. Todos ellos enseñaron a audiencias internacionales, a pesar de la existencia de una columna vertebral de estudiantes nacionales de Francia, de los estados alemanes o de las provincias holandesas. Sorprendentemente Italia, que había dominado la formación botánica a principios del siglo XVI yXVII, ya no es parte de la imagen. En lo que respecta a los botánicos británicos, aparecen entre los seguidores de Tournefort y Boerhaave. Otro rasgo característico de la época era la asociación entre la botánica, la medicina, especialmente la Materia medica, factor que explica la elevada proporción de médicos y catedráticos en medicina entre el subconjunto mixto. Esta proporción, que alcanzan $71 \%$ en el inicio de las carreras de los botánicos, se reduce significativamente hasta el $38 \%$ hacia el final de las mismas. De modo parecido, la proporción de "botánicos profesionales" (botánicos reales y botánicos Pensionnaires, catedráticos en botánica, jardineros) dentro de ese mismo subconjunto, se incrementa desde el 15\% para la primera posición estable hasta el $45 \%$ al final del cursus honorum.

Desde un punto de vista cronológico, los otros 2 subconjuntos deben considerarse ambos característicos de la situación en la segunda mitad del siglo XVIII. El subconjunto francés, que puede ser entendido como la prolongación del subgrupo asociado a Tournefort, está asentado principalmente en el contexto institucional ofrecido por el Jardin du Roi y la Academie des Siences en París, y de modo subsidiario en la facultad de medicina de Montpellier. La proporción de catedráticos en medicina es del $25 \%$ al principio sus carreras (en contraste con el $71 \%$ en el 
REDES- Revista hispana para el análisis de redes sociales

Vol.21,\#7, Diciembre 2011

http://revista-redes.rediris.es

subconjunto mixto), y del $15 \%$ al final de sus carreras (en oposición a $38 \%$ ). Por otra parte, la proporción de "botánicos profesionales" al principio sus carreras alcanza $29 \%$ (en oposición al $15 \%$ ) y el $51 \%$ (en oposición al $45 \%$ ) al final de las mismas. Un puñado de académicos retirados, botánicos y guardianes de herbarios pudieron practicar la botánica como especialistas a tiempo completo y crear una masa crítica de profesionales interconectados rompiendo con la asociación tradicional de la botánica con la medicina. Los destacados logros de los Jussieu, es decir, el desarrollo de una clasificación natural de las plantas, se benefició de estas circunstancias favorables.

El subconjunto sueco-germánico, que está claramente centrado en la figura de Linné y su sistema de clasificación sexual de las plantas, tiene un carácter nacional menos marcado que el francés, a pesar de que el $60 \%$ de sus miembros son suecos y daneses. Si bien la asociación tradicional entre la botánica y la medicina también se había relajado en comparación con los tiempos de Boerhaave, la ciencia las plantas no había alcanzado el grado de autonomía que tenía el conjunto francés. El número de practicantes y representantes de otras profesiones médicas alcanzaba el $41 \%$ en el principio de sus carreras y el $22 \%$ más tarde en sus vidas, una situación cercana a la media entre el subconjunto francés y el subconjunto mixto. Por otra parte, el grado de profesionalización de los botánicos era muy parecido entre el subconjunto sueco y el francés, con un $30 \%$ en el inicio de sus carreras y un $50 \%$ al final de ellas. Aparentemente, el programa de Linné para describir la riqueza de la Creación y la clasificación de los numerosos recursos vegetales a disposición de la humanidad y de la nación, simularon la profesionalización de la botánica. En comparación con el subconjunto francés, el subconjunto sueco-germánico incluye menos representantes de las clases altas y medias del Antiguo Régimen (terratenientes, clero, abogados, funcionarios), y posiblemente también menos individuos dedicados al comercio, la manufactura, la artesanía y otras profesiones de clase media. A pesar de la mayor proporción de catedráticos, la proporción de hombres de ciencia de primer rango y particularmente de académicos es menor que en el subconjunto francés. El hecho de que la clasificación de Linné siguiera un método más simple, evidentemente le aseguró una mayor popularidad, especialmente entre los botánicos de $2^{\circ}$ rango e incluso más entre los amateur (Curis, 1993). Sin embargo, su frecuente asociación con la historia natural con fines pragmáticos asociados a la agricultura o a la farmacia, pueden haber producido un estilo de botánica menos "académico" que aquél practicado por los Jussieu y sus discípulos. 
REDES- Revista hispana para el análisis de redes sociales

Vol.21,\#7, Diciembre 2011

http://revista-redes.rediris.es

\section{Evolución global y contrastes nacionales}

La evolución global de todo el conjunto de botánicos confirma las características que se observan en el subconjunto de botánicos interconectados. También destacan algunas diferencias estructurales entre sistemas nacionales de educación científica. Por ejemplo, no menos del $67 \%$ de los botánicos formados antes de 1740 tenían estudios en medicina (los nacidos antes de en 1720), una proporción que desciende a 55\% para aquellos formados entre 1740 y 1780 (es decir, nacidos entre 1720 y 1760 ) y al $50 \%$ después de 1780 (nacidos entre 1761 y 1805). Por otra parte, la cifra de académicos formados en filosofía, o en ciencia, que era muy baja antes de principios de 1740 , creció con la creación de nuevas plazas en muchas facultades de filosofía y en jardines botánicos. Entre los botánicos formados durante el período de la Ilustración (entre 1740 y 1780), las características más sorprendentes son la creciente afluencia al Jardin du Roi en París, pero también el creciente interés por la botánica de personas formadas en artes, en derecho, y sobre todo en teología. Finalmente, el período entre principios de 1780 y finales de 1820 se caracteriza por la mayor proporción de botánicos formados en la ciencia, con el desarrollo de la formación universitaria en ciencia, especialmente dentro de las facultades alemanas de filosofía. El resultado más visible de este desarrollo institucional es la creciente proporción de botánicos alemanes destacados ("a") entre los especialistas del tercer período: representan el $34 \%$ de esta élite después de 1780 , en oposición al pequeño $6,5 \%$ en el primer período (antes de 1740 ) y el ínfimo $4 \%$ del 20 período (entre 1740 y 1780 ). Si se considera a toda la comunidad de botánicos de tipo "a" y "b", la proporción de alemanes se incrementará más modestamente, desde el $31 \%$ y el $26 \%$ en los 2 primeros períodos al $36 \%$ en el último período.

Otro cambio a nivel global afecta a la movilidad internacional de los jóvenes estudiantes en botánica. Los movimientos registrados entre áreas "nacionales" muestran una tendencia decreciente a lo largo del siglo. Durante el primer período (antes de 1740), por lo menos el $20 \%$ de los botánicos pasaron un semestre o más en una universidad extranjera, una proporción que fue reducida hasta el 14,5\% en el segundo período y hasta el $9 \%$ en el tercer período. La proporción de botánicos que hicieron la mayoría de sus estudios en el extranjero era del $13 \%$ en el primer período, del $10 \%$ en el segundo, y del $5,5 \%$ en el tercer período. $Y$ en lo que respecta a la proporción de futuros botánicos que estudiaron en más de 2 universidades diferentes (peregrinatio academica) era del $13 \%$ en el primer período, pero declinó hasta $7 \%$ en el segundo período y a $6 \%$ en el tercero. Por lo 
REDES- Revista hispana para el análisis de redes sociales

Vol.21,\#7, Diciembre 2011

http://revista-redes.rediris.es

tanto, se observa que la tendencia a largo plazo consiste en reducir la movilidad de estudiantes a nivel internacional, pero también intra-nacional, tanto en medicina como ciencia, por lo menos para aquellos que más tarde tomaron la investigación en botánica profesionalmente. Queda fuera de duda el carácter crecientemente nacional, y también local, de la educación en botánica.

Una consecuencia posible es que la disponibilidad de cursos científicos en botánica y en ciencias naturales en un número más amplio de ciudades y de países europeos, no contribuyera a reducir las diferencias entre sistemas educativos en el siglo XVIII. Si analizamos la evolución de las cualificaciones de los botánicos entre 1670 y 1830, así como la elección de universidades y otros lugares de formación, se pone de relieve un agudo contraste entre, de una parte, los académicos formados en estados con sistemas universitarios altamente desarrollados, como los alemanes y los italianos, y por la otra parte, aquellos formados fundamentalmente en jardines botánicos, reales o privados, como los franceses o los británicos.

En el caso de Alemania, la importancia del sistema universitario tradicional explica la elevada proporción de médicos formados en medicina en los 2 primeros períodos $(80 \%$ y $66 \%)$ e incluso el 30 (50\%). En este tercer período, la creciente oportunidad para los botánicos de ser formados como científicos en las facultades de filosofía favoreció la elección de universidades modernizadas como las del Göttingen, Berlín y Erlangen- Munich en detrimento de otras más tradicionales como Leipzig, Altdorf, o incluso la Leyden en el extranjero. También en Italia, la elevada densidad de universidades explica la elevada proporción de montañeros con una formación médica en los periodos dos y tres (66\% y $60 \%$ ). En el tercer período, la creación de nuevas cátedras en botánica explica el súbito incremento de especialistas italianos en las plantas y en la agricultura (de 11:09 especialistas en los dos primeros períodos hasta 23 en el tercero). Por el contrario el declive de la botánica holandesa entre los períodos uno y dos (de 10 a 5 especialistas), así como de la botánica sueca entre los periodos dos y tres (de 18 a 9 especialistas) parece estar asociado a un estancamiento de las universidades nacionales de Leyden y Uppsala, por lo menos en las áreas de botánica y de ciencias naturales. Lo mismo podría ser verdad para Basilea en Suiza dentro del tercer período, incluso si su declive fue compensado en gran medida por el ascenso de Ginebra. 
REDES- Revista hispana para el análisis de redes sociales

Vol.21,\#7, Diciembre 2011

http://revista-redes.rediris.es

En Francia, el declive de la facultad médica de Montpellier en el segundo período (Ilustración) fue compensada por el ascenso del Jardin du Roi, de modo que el número de nuevos botánicos para cada período se mantiene estable (de 34 el primero a 30 el $2^{\circ}$ y 30 en el tercer también). En el tercer período, el dominio exclusivo de París en la formación de la materia botánica no produjo la misma renovación que en Alemania (de 4841 en los 2 primeros períodos a 97 en el $3^{\circ}$ ) ni que en Italia, a pesar de la creación de la Universidad imperial y del desarrollo extraordinario de nuevas instituciones médicas. A principios del siglo XIX, los principales representantes de la clasificación natural diseña la por los Jussieu (como Candolle, R. Brown, Kunth, Cavanilles) estaban sentados en países extranjeros. En lo que respecta a los botánicos británicos, sabemos que muchos de ellos se formaron en el extranjero en los primeros 2 periodos. Entre aquellos que estudiaron en universidades británicas, la mayoría tenía un currículum en artes, teología o derecho, todos ellos estudios considerados como apropiados para caballeros no profesionales o no especializados. A ellos se unieron numerosos jardineros $y$ horticultores que no atendían la Universidad.

\section{Conclusión}

Desarrollar un análisis de redes sociales sobre la historia de la botánica del siglo XVIII es una tarea compleja, que implica centrarse en la emergencia de un paradigma disciplinario nuevo en lugar de describir una sucesión de descubrimientos y de teorías. Este cambio de perspectiva hace que algunos hechos ya conocidos aparezcan bajo una nueva luz, a menudo como resultados de la interacción personal e intelectual entre académicos. En este caso, la nueva perspectiva consiste en mostrar el fenómeno como el resultado de la creación de dos sistemas educativos nacionales -uno en Francia, otro en Suecia- en los cuales la botánica se impartió independientemente de la medicina. Sin embargo, la emancipación de los futuros botánicos de la prácticamente obligatoria formación en medicina, así como de la práctica médica, parecía ser una tendencia global. Era especialmente visible en Alemania, con el desarrollo de la enseñanza en ciencias dentro de las facultades de filosofía. También era visible en Gran Bretaña, con las nuevas posibilidades de formación que ofrecían la Universidad de Edimburgo y diversos jardines botánicos en Londres; e incluso fue visible en Italia, con el renovado interés de las universidades en la agricultura. 
REDES- Revista hispana para el análisis de redes sociales

Vol.21,\#7, Diciembre 2011

http://revista-redes.rediris.es

Otra tendencia bien conocida es el interés de los pensadores de la Ilustración y las élites intelectuales por la utilidad y la contemplación de la naturaleza en general, y por el hecho de este clima intelectual impulsó a un número creciente de caballeros, religiosos y profesionales formados en las artes, la teología y en el derecho a practicar la botánica como una vocación vital. La consecuencia predecible -si bien nunca anunciada hasta el momento-espacio es que el número de botánicos a sueldo se dobló entre 1700 y 1770 , y se dobló de nuevo entre 1770 y 1830 , de modo que se crearon mejores oportunidades de formación en un número creciente de países y de ciudades a lo largo de Europa. Por lo tanto, la necesidad de trasladarse a países extranjeros, o incluso a otras universidades dentro de la misma area nacional, se redujo de modo continuado en beneficio de instituciones locales o nacionales. La mezcla de nacionalidades de los botánicos del siglo XVIII, que se formaron mayoritariamente en Holanda (Leyden y Amsterdam) dio paso, en la $2^{a}$ mitad del siglo, a una pauta de formación más diversificada, dominada por un grupo francés basado en París y un grupo sueco-germánico formado en Uppsala. Estos 2 grupos famosos, que sirvieron como núcleos de comunidades nacionales de botánicos, eran sólo los ejemplos más visibles de un conjunto emergente de comunidades académicas definidas geográficamente. Las Mejoras en la documentación así como las técnicas marginadas de investigación deberían ayudarnos a detectar la existencia de otras comunidades de botánicos, ya sean nacionales o locales.

Por supuesto, eran frecuentes en el siglo XVIII los botánicos sin vínculos de formación registrados tanto en Italia, como en Gran Bretaña, Alemania, y los dominios de Habsburgo o incluso en las ciudades de las provincias de Suecia y de Francia. Por otra parte, los franceses de París y de Montpellier estaban estrechamente interconectados, como lo estaban los botánicos suecos de Uppsala, Estocolmo, Lund, y Abo, los holandeses de distintas provincias e incluso los suizos, ya fueran de habla alemana (conectados al grupo mixto de Boerhaave) o los de habla francesa (cercanos al grupo francés de los Jussieu). Con todo, la consideración de otros tipos de vínculos delinearía otras comunidades botánicas, ya fueran nacionales o no. De hecho, los vínculos de patronazgo eran muy estrechos en Gran Bretaña, especialmente alrededor de Joseph Banks (1743-1820 durante el tiempo de su presidencia vitalicia de la "Royal Society" (Gascoigne, 1998), y también antes alrededor de Hans Sloane (1660-1753) y de Peter Collinson (16941768), y más tarde alrededor de William Jackson Hooker (1785-1865). En San Petersburgo, las posiciones académicas bien remuneradas permitieron al gobierno 
REDES- Revista hispana para el análisis de redes sociales

Vol.21,\#7, Diciembre 2011

http://revista-redes.rediris.es

ruso importar botánicos formados de Alemania y otros países, mientras que la política colonial de la España de la ilustración ofrecía múltiples oportunidades a los botánicos nacionales para explorar la flora de América del Sur.

Los botánicos alemanes no tenían un centro nacional, excepto quizá en Berlín en el siglo XIX. Antes de eso, tanto el jardín botánico de Berlín como las facultades de medicina de Leipzig, Göttingen y Erlangen tuvieron a sus figuras principales y sus periodos de climax, a pesar de que ninguno de ellos fue capaz de hacer perdurar su posición dominante. El modo en que la tradición de Linné se transformó en diversas líneas de sucesión después de 1770, así como las influencias mutuas establecidas por la circulación de profesores y estudiantes muestran la coexistencia de distintas tradiciones locales dentro del Sacro Imperio. Este contexto de mejora de oportunidades y de creciente estímulo fue el sustrato intelectual en la emergencia de un creciente número de botánicos de primer orden después de 1780 .

A pesar de que un creciente número de facultades en las universidades y de jardines botánicos proporcionaron oportunidades para una educación formal en la botánica a lo largo del siglo XVIII, no se pudo apreciar una estandarización real de la formación antes de 1830 aproximadamente. Pero al contrario, después de 1740, se formó una gran diversidad de actores en las facultades de la universidad distintas a las de medicina, que luego tendrían carreras en profesiones distintas a ésta, incluyendo por supuesto la botánica. La creciente influencia del utilitarismo y el desarrollo de una sensibilidad pre-romántica hacia la naturaleza fueron factores adicionales en el interés hacia la botánica por parte de las élites académicas de Europa. Al mismo tiempo, la existencia de un paradigma para la disciplina específica de la botánica era cada vez más perceptible, por lo menos para un núcleo duro de botánicos profesionales. Sin embargo, el desarrollo de una educación y de instituciones de investigación a nivel nacional, y la creciente competición entre monarquías por el "imperio de la ciencia", produjeron una geografía diferenciada en la práctica y en la formación científicas.

Mientras el sistema internacional de intercambios ordinarios de información y de materiales (la "República de las letras") permaneció intacto hasta 1780, el carácter nacional de la ciencia académica en Francia y de las reformas universitarias en Alemania, así como las políticas utilitarias e imperialistas desarrolladas por Suecia, Gran Bretaña, Italia, Rusia y España conspiraron para producir una geografía diferenciada nacionalmente de enclaves científicos que afectaron al desarrollo de la botánica. En lo que respecta al trabajo de campo de colecta y clasificación, también 
REDES- Revista hispana para el análisis de redes sociales

Vol.21,\#7, Diciembre 2011

http://revista-redes.rediris.es

tuvieron una influencia importante en el desarrollo de comunidades locales de aficionados y en botánicos aislados en áreas provinciales y periféricas.

De cualquier modo, las oportunidades de formación y las relaciones entre maestros y discípulos son poco más que la puerta de entrada al mundo de la botánica moderna. Los académicos jóvenes con ganas de alcanzar un estatus profesional o de encontrar medios para financiar su investigación en botánica debían asegurarse la protección de patrones poderosos o de disfrutar de la ayuda de sus familiares. Sus consiguientes carreras dentro de la "República de los botánicos" estarían después condicionadas por las influencias intelectuales, por los intercambios de información y de especímenes, así como por las colaboraciones significativas que se desarrollarían con los colegas. Todas estas dimensiones pueden estar sujetas a un análisis de redes. Por lo tanto, son las que más fácilmente revelarán dimensiones adicionales de la geografía en evolución de las comunidades botánicas en la Europa del siglo XVIII.

\section{Bibliografía}

Batagelj V., Mrvar A.(1998). Pajek - Program for Large Network Analysis, Connections, 21, 47-57.

Bots, Hans \& Waquet, Françoise (1997). La République des Lettres, Paris, Belin De Boeck.

Bungener, Patrick (2007). La botanique au service de l'agriculture. L'exemple des savants genevois, in Paul Robin., J.-P. Aeschlimann \& C. Feller (éd.), Histoire et agronomie: entre ruptures et durée, Paris, IRD, 285-302.

Bynum, William F., Browne, Janet \& Porter, Roy (eds), The Macmillan Dictionary of the History of Science, London, Palgrave Macmillan, 1983

Dauser, Regina, Stefan Hächler, Michael Kempe, Franz Mauleshagen, Martin Stuber (ed.) (2008). Wissen im Netz. Botanik und Planzentransfer in europäischen Korrespondenznetzen des 18. Jahrhunderts, Berlin, Akademie Verlag.

De Nooy Wouter, Mrvar Andrej and Batagelj Vladimir (2005). Exploratory social network analysis with Pajek, Cambridge, Cambridge University Press.

DSB: see Gillispie, Charles C. (dir.)

Duris, Pascal (1993). Linné et la France (1780-1850), Genève, Droz. 
REDES- Revista hispana para el análisis de redes sociales

Vol.21,\#7, Diciembre 2011

http://revista-redes.rediris.es

Elina, Olga (2008), "Private Botanical Gardens in Russia: Between Noble Culture and Scientific Professionalization", Studies in the History of Gardens and Designed Landscapes, 28 / 3-4.

Frängsmyr, Tore (ed.) (1989), Science in Sweden. The Royal Swedish Academy of Sciences, 1739-1989, Canton (MA), Watson Publishing International.

Fries, Rob E. (1950). A short history of botany in Sweden, Uppsala, Almqvist \& Wiksell.

Gascoigne, John (1998). Science in the Service of Empire: Joseph Banks, the British State and the Uses of Science in the Age of Revolution, Cambridge, Cambridge University Press.

Gascoigne, John (2002). Cambridge in the age of the Enlightenment. Science, religion and politics from the Restoration to the French Revolution [1989], Cambridge, Cambridge University Press.

Gascoigne, Robert M. (1984). A Historical Catalogue of Scientists and Scientific Books. From the Earliest Times to the Close of the Nineteenth Century, New York and London, Garland Publishing.

Gillispie, Charles C. (dir.) (1990). Dictionary of Scientific Biography, New York, Scribner's sons, 1970-1980. New York: Charles Scribner's Sons.

Girvan, M. and Newman, M. E. J., (2002). Community structure in social and biological networks, Proceedings of the Natlonal Academy. of Science,. USA, 99, 7821-7826.

Haechler, Stefan (2008). Pflanzentransfer in der Korrespondenz Albecht von Hallers (1708-1777), in Regina Dauser \& al (eds), Wissen im Netz. Botanik und Pflanzentransfer in europäischen Korrespondenznetzen des 18. Jahrhunderts, Berlin, Akademie Verlag, 201-218.

Hannaway, Owen (1975). The Chemists and the Word: The Didactic Origins of Chemistry, Baltimore, Johns Hopkins University Press.

Hanneman, Robert A. and Riddle, Mark (2005). Introduction to social network methods, Riverside, CA: University of California.Macmillan: see Bynum \& al. (eds)

Morton, A. G. (1981). History of botanical science, London, Academic Press. 
REDES- Revista hispana para el análisis de redes sociales

Vol.21,\#7, Diciembre 2011

http://revista-redes.rediris.es

Müller-Willie, Staffan (1999). Botanik und weltweiter Handel. Zur Begründung eines natürlichen Systems der Pflanzen durch Carl von Linné (1707-1778), Berlin, Verlag für Wissenschaft und Bildung.

Nickelsen, Kärin (2008), Korrespondenzen und andere Netze: Die Konstruktion von Pflanzenbildern im 18. Jahhundert, in Regina Dauser \& al (eds), Wissen im Netz. Botanik und Pflanzentransfer in europäischen Korrespondenznetzen des 18. Jahrhunderts, Berlin, Akademie Verlag, 113-133.

Önnerfors, Andreas (2008), Die Verbreitung Linnéscher Naturalhistorie in SwedishPommern im 18. Jahhundert, in Regina Dauser \& al (eds), Wissen im Netz. Botanik und Pflanzentransfer in europäischen Korrespondenznetzen des 18. Jahrhunderts, Berlin, Akademie Verlag, 91-111.

Ridder-Symoens, Hilde de (1989). Italian and Dutch universities in the 16th and 17th centuries, in C. S. Maffioli \& L. C. Pahn (ed.), Italian Scientists in the Low Countries in the 17th and 18th centuries, Amsterdam, Atlanta (GA) 31-64.

Sigrist, René (2008a). La République des sciences: essai d'analyse sémantique, Dix-Huitième Siècle, 40, 333-357.

Sigrist, René (2008b). Correspondances scientifiques du $18^{\mathrm{e}}$ siècle : présentation d'une méthode de comparaison, Revue Suisse d'Histoire, 58/2, 147-177.

Sigrist, René (2009). Scientific Networks and Frontiers in the Golden Age of Academies (1700-1830). An essay with new data, in Helmut Eberhart and Jürgen Barkhoff (eds.), Networking across Borders and Frontiers. Demarcation and Connectedness in European Culture and Society, Frankfurt a.M., Peter Lang, 35-65.

Sigrist, René (2011). On the social characteristics of the 18th century botanists, in André Holenstein, Hubert Steinke \& Martin Stuber (eds), Scholars in Action. The Practice of Knowledge and the Figure of the Savant in the $18^{\text {th }}$ century, Leiden and Boston, Brill, (in print).

Spary, Emma C. (2008). Botanical Networks revisited, in Regina Dauser \& al (eds), Wissen im Netz. Botanik und Pflanzentransfer in europäischen Korrespondenznetzen des 18. Jahrhunderts, Berlin, Akademie Verlag, 47-64.

Steinke, Hubert (2008). Gelehrte - Liebhaber - Oekonomen. Typen botanischer Briefwechsel, in Regina Dauser \& al (eds), Wissen im Netz. Botanik und Pflanzentransfer in europäischen Korrespondenznetzen des 18. Jahrhunderts, Berlin, Akademie Verlag, 135-147. 
REDES- Revista hispana para el análisis de redes sociales

Vol.21,\#7, Diciembre 2011

http://revista-redes.rediris.es

Stuber, Martin (2008). Kulturpflanzentransfer im Netz der Oekonomischen Gesellschaft Bern, in Regina Dauser \& al (eds), Wissen im Netz. Botanik und Pflanzentransfer in europäischen Korrespondenznetzen des 18. Jahrhunderts, Berlin, Akademie Verlag, 229-270.

Stuber, Martin, Haechler, Stefan, Krempel, Lothar \& Ruisinger, Marion Maria (2008). Exploration von Netzwerken durch Visualisierung. Die Korrespondenznetze von Banks, Haller, Heister, Linné, Rousseau, Trew und der Oekonomischen Geselleschaft Bern, in Regina Dauser \& al (eds), Wissen im Netz. Botanik und Pflanzentransfer in europäischen Korrespondenznetzen des 18. Jahrhunderts, Berlin, Akademie Verlag, 347-374.

Taton, René (1964). Enseignement et diffusion des sciences en France au XVIIIe siècle, Paris, Hermann.

Williams, Roger L. (2001). Botanophilia in $18^{\text {th }}$-century France. The Spirit of Enlightenment, Dordrecht-Boston-London, Kluwer Academic Publishers.

World Biographical Information System (WBIS), edited on microfiches by Saur AG, München (data for European scholars also avaliable on-line). 